NBER WORKING PAPER SERIES

\title{
DERIVING RISK ADJUSTMENT PAYMENT WEIGHTS TO MAXIMIZE EFFICIENCY OF HEALTH INSURANCE MARKETS
}

\author{
Timothy J. Layton \\ Thomas G. McGuire \\ Richard C. van Kleef \\ Working Paper 22642 \\ http://www.nber.org/papers/w22642 \\ NATIONAL BUREAU OF ECONOMIC RESEARCH \\ 1050 Massachusetts Avenue \\ Cambridge, MA 02138 \\ September 2016
}

Research for this paper was supported by the National Institute of Mental Health (R01 MH094290), the National Institute of Aging (P01-AG032952), and the Laura and John Arnold Foundation. In addition, Layton was supported by NIMH T32 019733. We are grateful to Frank Bakker, Savannah Bergquist, Jay Bhattacharya, Michael Chernew, Frank Eijkenaar, Randy Ellis, Michael Geruso, Alice Ndikumana, Sharon-Lise Normand, Sherri Rose, Mark Shepard, Anna Sinaiko, Wynand van de Ven, the participants of the Economics Seminar Series in Leuven, Belgium (February 9, 2016), the Health Insurance Seminar Series in Rotterdam, the Netherlands (February 10, 2016), and the American Society of Health Economics (June 13, 2016) for comments on a previous draft. We gratefully acknowledge the Dutch Ministry of Health and the Association of Health Insurers for providing access to the administrative data. The authors are solely responsible for the analyses and conclusions. The views expressed herein are those of the authors and do not necessarily reflect the views of the National Bureau of Economic Research.

NBER working papers are circulated for discussion and comment purposes. They have not been peer-reviewed or been subject to the review by the NBER Board of Directors that accompanies official NBER publications.

(C) 2016 by Timothy J. Layton, Thomas G. McGuire, and Richard C. van Kleef. All rights reserved. Short sections of text, not to exceed two paragraphs, may be quoted without explicit permission provided that full credit, including $\odot$ notice, is given to the source. 
Deriving Risk Adjustment Payment Weights to Maximize Efficiency of Health Insurance Markets

Timothy J. Layton, Thomas G. McGuire, and Richard C. van Kleef

NBER Working Paper No. 22642

September 2016

JEL No. I11,I13,I18

\begin{abstract}
Risk adjustment of payments to health plans is fundamental to regulated competition among private insurers, which serves as the basis of national health policy in many countries. To date, estimation and evaluation of a risk adjustment model has been a two-step process. In a first step, the risk-adjustment payment weights are estimated using statistical techniques, generally ordinary-least squares, to maximize some statistical objective such as the R-squared; then, in a second step, the risk adjustment model is evaluated, usually with simulation methods, but without an explicit framework describing the objective of the model. This paper first develops such a framework and then uses it to replace the two-step "estimate-then-evaluate" approach with a onestep "estimate-to-maximize-the-objective" approach. We assume that the objective of risk adjustment is to minimize the loss from service-level distortions due to adverse selection incentives, and we derive expressions for the service-level distortions as a linear function of the risk adjustment payment weights. We show that when the number of risk adjustor variables exceeds the number of decisions plans make about service allocations, incentives for service-level distortion can always be eliminated. Under these circumstances the welfare maximizing payment weights can be found with a constrained least-squares regression where the constraints are the conditions under which plan actions achieve efficiency. We illustrate this method with the data used to estimate risk adjustment payment weights in the Netherlands ( $\mathrm{N}=16.5$ million). When the number of "services" exceeds the number of available risk adjustors, however, it is not possible to eliminate incentives for service-level distortion. In this case, a regression on transformed data produces the (second-best) payment weights that minimize welfare loss.
\end{abstract}

Timothy J. Layton

Department of Health Care Policy

Harvard Medical School

180 Longwood Avenue

Boston, MA 02115

layton@hcp.med.harvard.edu

Thomas G. McGuire

Department of Health Care Policy

Harvard Medical School

180 Longwood Avenue

Boston, MA 02115

and NBER

mcguire@hcp.med.harvard.edu
Richard C. van Kleef

Institute of Health Policy and Management

Erasmus University Rotterdam

PO Box 1738

3000 DR Rotterdam

The Netherlands

vankleef@bmg.eur.nl 


\section{Introduction}

Health insurance markets are vulnerable to market failures related to adverse selection (Einav, Finkelstein, and Cullen 2010; Glazer and McGuire 2000). Risk adjustment (aka "risk equalization") of payments to health plans is a widely used policy intended to counter adverse selection problems and is a fundamental component of the regulated private health insurance markets that serve as the basis of national health policy in Germany, Israel, the Netherlands, Switzerland, and other countries, as well as of key sectors in the U.S., including the Medicare Advantage program for Medicare beneficiaries and the state-level Marketplaces created by the Affordable Care Act (2010). Each of these individual health insurance markets includes a payment system, which, depending on the country, adjusts plan payments to age, gender, geographic area, past or current medical diagnoses, past spending, and other characteristics of enrollees.

To date, the payment weights attached to the different individual characteristics included in a risk adjustment model used in a given health plan payment system have been generated using regression techniques, typically via an individual-level ordinary least squares (OLS) regression of total annual health care spending on the variables included in the model (risk adjustors). The payment to the insurer for a given enrollee is then effectively set equal to the predicted value the regression model generates for that enrollee. Such a method chooses payment weights that maximize the statistical "fit" (i.e., the R-squared) of plan revenues to costs at the individual level. However, as has been pointed out in previous work, it is unclear whether a statistical measure such as the R-squared is the "correct" objective function to maximize given the goals of either the regulator or the social planner (Glazer and McGuire 2002).

Indeed, empirical studies evaluating different risk adjustment models imply that maximizing the Rsquared is not the regulator's objective. Such studies tend to emphasize group-level fit of plan revenues to costs rather than individual-level fit. For example, Kautter et al. (2014) first estimated the federal model proposed for the U.S. Marketplaces using OLS, and then evaluated it by creating subgroups of individuals with particular characteristics and simulating average fit for each of these groups. McGuire et al. (2014) performed a similar evaluation of the Marketplace model. With data from the Netherlands, Van Kleef et al. (2015a) first estimated a risk adjustment model, and then merged survey information with health claims to check fit for various groups of people, including those with low physical self-rated health status and those reporting chronic conditions. As far as we know, however, no explicit underlying framework describes insurer behavior and market efficiency underlying the evaluation methods and measures used in these papers and by researchers and policymakers generally. In other words, there has been no explicit objective function for risk adjustment design. 
In this paper we attempt to improve upon the current methodology and advance the current literature in a number of important ways. We start with Glazer and McGuire (2002) which uses a model of the behavior of a profit-maximizing insurer to (1) study incentives faced by insurers to inefficiently ration certain services and (2) develop a method for estimating risk adjustment weights that neutralize these incentives when the number of services is smaller than the number of variables in the risk adjustment model. Our key innovations are to (1) move beyond incentives and solve for the equilibrium service-level allocations insurers will offer in a symmetric competitive equilibrium under a given plan payment system and (2) extend the model to relate these (distorted) allocations (as well as the payment system that generated them) to consumer utility and social welfare. These innovations allow us to make a number of novel and important advances. First, we are able to show the set of (implausible) conditions under which the R-squared is the correct objective function to be maximized by the regulator. Second, we generate a welfare-founded measure of payment system performance. Third, we are able to develop simple, general, and easy-to-implement methods for deriving optimal risk adjustment payment weights that maximize social welfare, even in the entirely plausible, but previously unexplored, case where the number of services exceeds the number of risk adjusters.

These methods can effectively replace the conventional two-step "estimate-then-evaluate" approach, where policymakers and researchers first estimate payment weights for a given risk adjustment model using a statistical objective function and then second evaluate the weights using a different set of criteria, with a relatively simple one-step "estimate-to-maximize-the-objective" approach, where the regulator's true objective function is used to estimate the payment weights. For any risk adjustment model for which the number of risk adjustor variables exceeds the number of decisions plans make about service allocations, a simple constrained regression of healthcare spending on the risk adjustors in the model produces the payment weights that maximize the objective function. In other cases, where the risk adjustment model includes fewer risk adjustors than plan decisions, there is typically no set of payment weights that fully eliminate incentives for service-level distortion. Under these circumstances the optimal (second-best) payment weights can be found via a standard OLS regression on a transformation of the data and the risk adjustors. Thus, the methods we propose improve on both the status quo and the more sophisticated methods developed in the academic literature (i.e., Glazer and McGuire 2002) while maintaining the simplicity and minimal computational burden of those methods.

Following our modeling exercise in Section 3, we use data from the Netherlands to both present our welfare-founded measure of payment system performance and to demonstrate the implementation of our new optimal payment weight estimation methods. The data for our empirical demonstration, described in Section 4, are the actual data used to estimate risk adjustment payment weights in the Netherlands, and include multiple years of information on medical care use and individual demographic and risk characteristics, 
on the full 16.5 million Dutch population. We replicate the payment weights used in the 138-variable risk adjustment model in place for 2015, and compare these weights, and the welfare implications of the weights, to the weights produced by our efficiency loss-minimizing approach. The Dutch data are excellent for the purpose of this paper since the risk adjustment model has been refined based on many years of research and includes a large set of risk adjustor variables. For estimation, we take the set of risk adjustor variables as given, using the actual risk adjustors employed in the Dutch model. ${ }^{1}$ In Section 4 we also describe how we operationalize assumptions about the level at which plans make allocation decisions, how (expected) individual spending relates to total spending on a service and how we interpret the data in terms of efficiency of the current system. Finally, Section 4 describes the measures we use to characterize the efficiency of a risk adjustment model and its associated payment weights and the assumptions we invoke to allow us to implement our methods.

Empirical methods to estimate risk adjustment payment weights and results are described in Section 5 (and an associated appendix). We describe model fit, plan incentives and overall welfare loss associated with the weights generated by the current methods and the weights generated by the welfare-maximizing methods. An innovation of this paper is that because we employ an explicit model of plan behavior as a function of the risk adjustment payment weights, we can derive the service-level allocations insurers will offer in a competitive equilibrium under a given set of weights. Comparing equilibrium service-level allocations under different sets of payment weights allows us to characterize the spending implications by service of the alternative sets of weights. Comparing these equilibrium service-level allocations to the optimal service-level allocations presents an additional way to depict the improved efficiency properties of our proposed estimator. These equilibrium allocations are also an important component of the measure of welfare loss we present for each alternative set of weights we estimate for the Dutch model.

Section 6 contains what we believe to be a promising extension suggested by our model of insurer behavior and market efficiency. An estimation approach based on efficiency calls for an explicit statement of what is meant by efficiency and how this is manifest in the data. In Sections 4 and 5 we assume that the levels of spending observed in the data are efficient (following the implicit assumption in the existing risk adjustment literature). In Section 6 we show that our procedure for deriving payment weights can be modified to allow the regulator or researcher to specify the efficient levels of spending for each service for each individual. The idea is very simple and operational. Suppose a public authority believes that plans

\footnotetext{
${ }^{1}$ A risk adjustment model involves choice of risk-adjustor variables as well as the weights to be assigned to these variables. Economic criteria, primarily "gameability" and clinical criteria, primarily "meaningfulness," are typically considered together with incremental contributions to statistical fit when selecting the risk adjustor variables. See Kautter (2014) for discussion of this in the case of Marketplace risk adjustment, and Kronick and Welch (2014) and Geruso and Layton (2015) for empirical studies of "upcoding" in the case of Medicare Advantage plans. The loss functions we propose here could substitute for the use of "fit" in the decision about variables to include.
} 
currently (and in the data) spend too much on inpatient care for certain disease groups and too little on office-based care for the same conditions. Our analysis shows that the public authority can use the risk adjustment component of a health plan payment system to achieve its desired goals for spending targets. First, the regulator should modify individual-level spending in the data to be equal to the desired level. Then, the regulator should use modified spending, rather than actual spending, to estimate the payment weights. In simple terms, we propose that regulators risk adjust for the system they want, not the system they've got. Section 7 comments on some additional directions for research and policy.

\section{Objectives for Health Plan Payment}

Although risk-adjustment researchers acknowledge that risk adjustment is intended to reduce incentives for risk selection, in practice, statistical, not economic, criteria are used in estimation of payment weights used in risk adjustment models. In the two-step "estimate-then-evaluate" method of risk adjustment design referred to above, when done for policy, the first, "estimate" step is universally an OLS regression of individual-level spending on a set of risk-adjustor variables, with the estimated coefficients becoming the payment weights used in the risk adjustment component of the health plan payment system. ${ }^{2}$ Researchers have studied alternatives to maximizing R-squared with an OLS regression, with the most commonly proposed alternative being minimizing the Mean Absolute Prediction Error (MAPE) which applies a linear rather than a quadratic loss function to the actual-prediction gaps. ${ }^{3}$ Arguments for the less-common alternatives to R-squared, however, are generally made on statistical rather than economic grounds, and none, so far as we know, have been put into practice. ${ }^{4}$

Research papers concerned with the economics of health insurance markets and the inefficiencies due to adverse selection tend not to draw explicit implications for risk adjustment payment weights. ${ }^{5}$ In one strand of this literature, building on earlier work by Cutler and Reber (1998), Einav and Finkelstein and colleagues study one form of adverse selection inefficiency which results from sicker individuals tending to

\footnotetext{
2 There are some minor qualifications to this statement: coefficients in some of the Dutch risk adjustment models are constrained to avoid negative predicted spending. In the U.S., the Hierarchical Cost Categories (HCC)-based estimates, some coefficients are changed, post-estimation, so that clinical "hierarchies" are maintained.

${ }^{3}$ For example, see Van Barneveld et al. (2001) and Ettner et al., (2001). Van Veen et al. (2015) document that the MAPE is the second-most commonly used fit criterion in the research literature on risk adjustment. Note, however, that while the MAPE is often used in the "evaluate" step, it is not used for payment weight estimation, again implying that estimation methods maximize an objective function that differs from true policy objectives.

${ }^{4}$ Van Veen et al. (2015) summarize fit measures used in this literature, and document that the vast majority of papers use an R-squared statistic (or closely related) measure of fit of the risk adjustment model and/or predictive ratios with predicted values from the risk adjustment model in the numerator.

${ }^{5}$ A more extensive review of the literature on the inefficiency in health insurance due to adverse selection is contained in Layton, Ellis and McGuire (2015). That paper also proposes efficiency metrics for comparing health plan payment systems. It does not, however, use these metrics to derive estimators for risk adjustment payment weights.
} 
join more generous plans. ${ }^{6}$ This type of adverse selection forces the more generous plans to increase premiums in order to cover costs of the sicker enrollees, not just to cover costs due to more generous benefits. Consequently, the premium for the generous plan is "too high" and too few consumers choose it.

One option to deal with this form of adverse selection is risk rating of the premiums faced by enrollees, for example, charging sick people their full incremental costs (Bundorf, Levin, Mahoney, 2012). From a social point of view, however, this is often regarded as undesirable due to objectives related to affordability of health plans for the sick, equity in health plan pricing, and a desire to provide insurance against the "reclassification risk" of deteriorating health status (Handel, Hendel, and Whinston 2015). It is common in regulated competition policy settings to strictly limit allowed premium groups, sometimes even requiring each plan to charge only a single premium, as is true in the Dutch national health insurance system, and the Medicare Advantage program. ${ }^{7}$

Another option is risk adjustment. By transferring funds to the more generous plan when sicker individuals enroll, risk adjustment dampens the component of plan premium differences due to selection. The optimal policy transfers a set amount of funding to the more generous plan so as to offset the selection effect on the incremental premium. Given that the number of risk adjustor variables exceeds the number of plans and given that the risk composition of health plans is known when the risk adjustment model is estimated, there are innumerable combinations of risk adjustment payment weights that would succeed in effecting this transfer. A well-chosen simple subsidy set in advance for the generous plan would solve the problem - risk adjustment is not required to solve the Einav-Finkelstein sorting inefficiency. ${ }^{8}$

The second strand of the literature on adverse selection, and the one relevant here, is concerned with plans distorting their products to attract/deter individuals who are financial winners/losers, an activity referred to as "skimping," "service-level selection," or "indirect selection." Even when nominal coverage is regulated, plans, through network structure, provider payment, managed care algorithms and other measures, can favor or disfavor certain population groups or service areas. Theoretical papers in health economics have "solved" this problem in simple cases by finding payment weights to correct for selection incentives. ${ }^{9}$ We make two advances in relation to previous research. First, we specify an explicit loss function that can guide choice of payment weights when selection incentives cannot be fully eliminated. Second, our solution can be implemented empirically in a real-world risk adjustment payment context.

${ }^{6}$ Einav and Finkelstein (2011); Einav, Finkelstein and Levin (2010); Einav, Finkelstein and Cullen (2010).

${ }^{7}$ In the Netherlands premiums must be the same for all consumers opting for the same health plan. There are some options for rebates (see Section 4), but these are community-rated as well. Explicit risk-rating is not allowed.

${ }^{8}$ The risk adjustment fix must only be partial (second-best) because no single premium is capable of capturing the efficient set of incremental premiums necessary for fully efficient sorting among plan types. Risk adjustment (or subsidies) cannot overcome inefficiencies in plan choice due to limited premium categories. Bundorf, Levin and Mahoney (2012) and Geruso (2016) treat this issue in detail. See also Layton, Ellis and McGuire (2015).

${ }^{9}$ See Glazer and McGuire $(2000,2002)$. 
In this paper we follow the second strand of the literature on adverse selection - the strand where risk adjustment is necessary to improve efficiency - and assume the goal of risk adjustment is to incentivize plans towards first-best service-level allocations. A crucial difference with the existing literature is that the one-step method proposed in this paper supplies the efficiency loss function to be minimized to find the second-best risk adjustment payment weights when the first best is infeasible.

\section{Risk Adjustment Payment Weights to Minimize the Welfare Loss from Health Plan Payments}

In the presence of premium regulation incentives related to selection may lead health plans to distort their contracts away from the efficient allocation of health care services, undermining welfare. Our framework for measuring welfare loss due to inefficient allocations of health care spending is based on costs and benefits of health care. Welfare loss is driven by the gap between the efficient allocation to an individual and the allocation the individual would receive in equilibrium under a given health plan payment system. The measure thus applies to inefficiencies related to the services offered by health plans, and not to inefficiencies related to advertising or other plan actions distinct from the distortion of the health insurance contract itself and the benefits and costs of health care under that contract. ${ }^{10}$ Throughout this paper, we maintain the assumption that health plans compete in a market. ${ }^{11}$

After presenting the welfare metric, we start with a (very) special case of plan behavior where a plan can decide how much of a homogenous service, "health care," to provide to each enrollee. While this case is clearly overly simplistic - health care is more than one product - and unrealistic - plans cannot set spending person-by-person - it provides intuition for how we approach the problem. Furthermore, this case establishes the assumptions under which a conventional OLS regression provides the efficient risk adjustment payment weights. We then consider the more general (and realistic) case where a plan can make spending decisions at the service level.

\footnotetext{
${ }^{10}$ Lorenz (2015) considers how profit/loss incentives to plans affect wasteful marketing activities, and how these incentives can be ameliorated by risk adjustment.

${ }^{11}$ We acknowledge that the markets in which risk adjustment is used are unlikely to exhibit perfect competition in practice. We therefore justify our assumption of perfect competition by pointing out that the bulk of the previous economic literature on adverse selection and health plan payment also makes this assumption (see Glazer and McGuire (2000); Einav, Finkelstein, and Cullen (2010); and Bundorf, Levin, and Mahoney (2012). We extend that literature while maintaining its basic framework.
} 


\subsection{Welfare Loss}

We envision a setting in which plan premiums and demand-side cost sharing are regulated, and do not vary with the alternative risk adjustment payment weights we consider. This setting exactly matches many state Medicaid Managed Care markets in the U.S., and it comes close to fitting the Dutch national health insurance system, U.S. Marketplaces and other health insurance markets in which premiums and demand-side cost sharing are also highly regulated. ${ }^{12}$ The efficiency issue we focus on is the allocation of resources across various services provided to plan enrollees as a function of the risk adjustment payments.

In our model, each plan offers a contract consisting of $\mathrm{N}$ vectors of individual-level allocations of health care services measured in dollars. Individuals are indexed by $\mathrm{i}$, with $\mathrm{i}=1, \ldots, \mathrm{N}$, and services by s, with $\mathrm{s}=1, \ldots, \mathrm{S}$. A contract or allocation specifies the spending each person receives for each service:

$$
\mathbf{X}=\left[\begin{array}{ccc}
\mathrm{x}_{11} & \cdots & \mathrm{x}_{1 \mathrm{~S}} \\
\vdots & \ddots & \vdots \\
\mathrm{x}_{\mathrm{N} 1} & \cdots & \mathrm{x}_{\mathrm{NS}}
\end{array}\right]
$$

Let $\mathrm{x}_{\mathrm{i}}=\sum_{\mathrm{s}} \mathrm{x}_{\mathrm{is}}$ be the sum of spending across all services for person $\mathrm{i}$. Individuals value service $\mathrm{s}$ according to $\mathrm{v}_{\mathrm{is}}\left(\mathrm{x}_{\mathrm{is}}\right)$, with $\mathrm{v}_{\mathrm{is}}^{\prime}\left(\mathrm{x}_{\mathrm{is}}\right)>0$ and $\mathrm{v}_{\mathrm{is}}^{\prime \prime}\left(\mathrm{x}_{\mathrm{is}}\right)<0$. Let $\mathrm{x}_{\mathrm{is}}^{*}$ be the first-best level of $\mathrm{x}_{\text {is }}$ such that $\mathrm{v}_{\mathrm{is}}^{\prime}\left(\mathrm{x}_{\mathrm{is}}^{*}\right)=1$. Also let $\mathrm{x}_{\mathrm{is}}^{\mathrm{e}}$ be the level of $\mathrm{x}_{\mathrm{is}}$ the insurer provides individual $\mathrm{i}$ in equilibrium, partly in response to the riskadjusted plan payment. Thus, $x_{i}^{e}=\sum_{s} x_{i s}^{e}$ and

$$
\mathbf{X}^{\mathbf{e}}=\left[\begin{array}{ccc}
\mathrm{x}_{11}^{\mathrm{e}} & \cdots & \mathrm{x}_{1 \mathrm{~S}}^{\mathrm{e}} \\
\vdots & \ddots & \vdots \\
\mathrm{x}_{\mathrm{N} 1}^{\mathrm{e}} & \cdots & \mathrm{x}_{\mathrm{NS}}^{\mathrm{e}}
\end{array}\right]
$$

Net welfare for individual i under equilibrium contract $\mathbf{X}^{\mathbf{e}}$ is then $\mathrm{W}_{\mathrm{i}}\left(\mathbf{X}^{\mathbf{e}}\right)=\sum_{\mathrm{s}} \mathrm{v}_{\mathrm{is}}\left(\mathrm{x}_{\mathrm{is}}^{\mathrm{e}}\right)-\mathrm{x}_{\mathrm{i}}^{\mathrm{e}}$. Define $\Delta \mathrm{W}_{\mathrm{i}}\left(\mathrm{X}^{\mathrm{e}}\right)=\left[\sum_{s} \mathrm{v}_{\mathrm{is}}\left(\mathrm{x}_{\mathrm{is}}^{\mathrm{e}}\right)-\mathrm{x}_{\mathrm{i}}^{\mathrm{e}}\right]-\left[\sum_{\mathrm{s}} \mathrm{v}_{\mathrm{is}}\left(\mathrm{x}_{\mathrm{is}}^{*}\right)-\mathrm{x}_{\mathrm{i}}^{*}\right]$ as the welfare loss for individual $\mathrm{i}$ in equilibrium relative to the first-best. To make $\Delta \mathrm{W}$ operational, we take a (second-order) Taylor-series expansion of $\Delta \mathrm{W}_{\mathrm{i}}\left(\mathbf{X}^{\mathbf{e}}\right)$ around $\mathrm{x}_{\mathrm{is}}^{*}$ to yield

$\Delta \mathrm{W}_{\mathrm{i}}\left(\mathbf{X}^{\mathrm{e}}\right) \approx \frac{1}{2} \sum_{\mathrm{s}} \mathrm{v}_{\mathrm{is}}^{\prime \prime}\left(\mathrm{x}_{\mathrm{is}}^{*}\right)\left(\mathrm{x}_{\mathrm{is}}^{\mathrm{e}}-\mathrm{x}_{\mathrm{is}}^{*}\right)^{2}$

We can then sum the welfare loss described by (1) across the entire population as follows:

$$
\Delta \mathrm{W}\left(\mathbf{X}^{\mathrm{e}}\right) \approx \frac{1}{2} \sum_{\mathrm{i}} \sum_{\mathrm{s}} \mathrm{v}_{\mathrm{is}}^{\prime \prime}\left(\mathrm{x}_{\mathrm{is}}^{*}\right)\left(\mathrm{x}_{\mathrm{is}}^{\mathrm{e}}-\mathrm{x}_{\mathrm{is}}^{*}\right)^{2}
$$

\footnotetext{
${ }^{12}$ Risk adjustment can affect the differences in premiums across plans by mitigating any adverse selection contribution to plan premium differences. In a symmetric equilibrium in the health plan market, as we will assume below, this effect will not be present in equilibrium.
} 
Approximation (2) describes the total welfare loss given the equilibrium contract $\mathbf{X}^{\mathbf{e}}$. Welfare loss is proportional to the weighted sum of squared differences between the equilibrium and the first-best allocations where the weight is the second-derivative of the individual's valuation function of service $s$ at the optimal level of service $s$ for person i.

Equilibrium spending, as described by $\mathbf{X}^{\mathbf{e}}$, results from plan profit maximization in the market. These choices are a function of the payments received by the plan. The payment system generates payment $r_{i}$ for person $\mathrm{i}$, determined by the payment weights, $\beta_{\mathrm{k}}$, on the $\mathrm{k}$ risk adjustors, $\mathrm{z}_{\mathrm{k}}$, included in the risk adjustment model taken as given. Thus, $r_{i}=\sum_{k} \beta_{k} z_{i k}$, where $z_{i k}$ is the value of risk adjustor $\mathrm{k}$ for individual $i$. In this section we explain how we solve for each component of $\mathbf{X}^{\mathbf{e}}, \mathrm{x}_{\mathrm{is}}^{\mathrm{e}}$, (noting the necessary assumptions) given the risk adjustment model and its associated payment weights, using conditions of profit maximization and market equilibrium. In Section 4 below we explain how we use observed patterns of spending to define the optimal spending targets.

\subsection{One Homogenous Service, Perfect Foresight and Individual-level Discrimination: an OLS Regression Selects Optimal Payment Weights}

The risk-adjustment payment weights $\beta_{\mathrm{k}}$ that minimize (2) depend on what actions plans take; specifically, on the level at which health plans can set spending allocations. We begin with the unrealistic but instructive case in which there is one homogeneous service, consumers have perfect foresight (i.e. know exactly which line of the contract applies to them) and plans can discriminate at the individual level (e.g. shift a dollar of spending from individual 1 to individual 2). Specifically, assume a health plan can set the level of "health care spending" for each individual, $\mathrm{x}_{\mathrm{i}}$. In this case, competition forces each insurer to profit maximize at the zero-profit contract person-by-person, so in equilibrium, $x_{i}^{e}=r_{i}$. Applying the welfare metric (2),

$\Delta \mathrm{W}\left(\mathbf{X}^{\mathbf{e}}\right)=\frac{1}{2} \sum_{\mathrm{i}} \mathrm{v}_{\mathrm{i}}^{\prime \prime}\left(\mathrm{x}_{\mathrm{i}}^{*}\right)\left(\mathrm{r}_{\mathrm{i}}-\mathrm{x}_{\mathrm{i}}^{*}\right)^{2}$

If we substitute $r_{\mathrm{i}}=\sum_{\mathrm{k}} \beta_{\mathrm{k}} \mathrm{z}_{\mathrm{ik}}$ we get

$\Delta \mathrm{W}\left(\mathbf{X}^{\mathbf{e}}\right)=\frac{1}{2} \sum_{\mathrm{i}} \mathrm{v}_{\mathrm{i}}^{\prime \prime}\left(\mathrm{x}_{\mathrm{i}}^{*}\right)\left(\sum_{\mathrm{k}} \beta_{\mathrm{k}} \mathrm{z}_{\mathrm{ik}}-\mathrm{x}_{\mathrm{i}}^{*}\right)^{2}$

It is straightforward to see that the coefficient estimates from a weighted least squares regression of $\mathrm{x}_{\mathrm{i}}^{*}$ on $\mathrm{z}_{\mathrm{ik}}$, $\widehat{\beta}_{\mathrm{k}}$, where the individual-level regression weights are given by $\mathrm{v}_{\mathrm{i}}^{\prime \prime}\left(\mathrm{x}_{\mathrm{i}}^{*}\right)$, minimize (4) and, thus, minimize the welfare loss. Furthermore, if we make the assumption that $\mathrm{v}_{\mathrm{i}}^{\prime \prime}\left(\mathrm{x}_{\mathrm{i}}^{*}\right)$ is the same for all individuals, (4) further 
reduces so that the risk adjustment payment weights estimated from an (unweighted) ordinary least squares regression minimize the welfare loss. ${ }^{13}$ This implies that with one service, individual-level discrimination, and constant $\mathrm{v}_{\mathrm{i}}^{\prime \prime}\left(\mathrm{x}_{\mathrm{i}}^{*}\right)$ across individuals the coefficients that minimize the sum of squared errors minimize welfare loss. These coefficients can be found with an OLS regression in which $\mathrm{x}_{\mathrm{i}}^{*}$ is the dependent variable. This also implies that under these assumptions the R-squared statistic is an appropriate metric for assessing the performance of a risk adjustment model and its associated payment weights. We proceed by relaxing the "one homogeneous service" and "individual-level" discrimination assumptions, as well as the assumption that consumers have perfect foresight, and deriving a more general loss function and methods for minimizing that function.

\subsection{Risk Adjustment and Equilibrium Service-Level Plan Allocations}

This section relaxes some assumptions from Section 3.2. Specifically, we make the more realistic assumption that plans discriminate over a variety services rather than at the individual level and that consumers no longer have perfect foresight (i.e., they no longer know with certainty which line of the contract applies to them). Discrimination at the service level is general in that plans might have a large or a small number of service decisions to make. It is also general in the sense that a "service" could be defined not only on the basis of the type of health care (e.g., office-based care) but also on the basis of diagnosis within that type, or even on the basis of groups of patients, such as those living in a certain city, or on the basis of providers, such as mental health specialists or a particular specialty cancer hospital. Thus, a "service" could in principle be office-based care by nephrologists in Rotterdam. The right definition of "service" in a particular application depends on what level of discrimination is open to plans, where discrimination may be limited by both regulation and information constraints. For example, if a plan can increase/decrease funding to primary care, but is unable to differentiate between pediatric and adult primary care in its contracts, then in spite of the fact that pediatric and adult care are distinct services in a clinical sense, they can be aggregated and funding considered as one "decision" in terms of efficiency and the effect of risk adjustment on equilibrium spending.

While service-level discrimination obviously affects individuals, the discrimination works through the plan setting budgets or management rules at the service level. As with the special case described in Section 3.2, here we want to again describe the individual-by-service allocations, $\mathrm{x}_{\mathrm{is}}^{\mathrm{e}}$, an insurer will offer in a competitive equilibrium as a function of the risk adjustment payments. Finding the equilibrium allocations as a function of the risk adjustment payments requires characterization of a plan's profit maximizing decision

\footnotetext{
${ }^{13}$ The constant $\mathrm{v}_{\mathrm{i}}^{\prime \prime}\left(\mathrm{x}_{\mathrm{i}}^{*}\right)$ means, in effect, that the welfare loss of the squared deviation from efficiency is weighted equally across individuals. With one service, a constant second derivative assumes that the slope of the demand curve around the optimal spending is the same for each person.
} 
with respect to spending on particular services. Profit maximization takes into account the costs of spending on a particular service as well as the net revenue of members that are expected to enroll in a plan as a function of service-level spending (i.e., selection). Some services attract members whose revenue exceeds their cost, incentivizing the plan to fund these services more generously. Other services attract members whose cost exceeds their revenue, incentivizing the plan to tighten rationing for these services. We maintain the assumption that competition enforces zero profits among plans.

Given the spending decisions of all other plans, the probability that a particular consumer enrolls in plan $j$ is a function of the individual's valuation of the services the consumer expects to be provided by plan $j$. We assume that an individual's valuation of a plan depends additively on the sum of the valuations of the s services, $\mathrm{v}_{\mathrm{i}}(\widehat{\mathbf{X}})=\sum_{\mathrm{s}} \mathrm{v}_{\mathrm{is}}\left(\hat{\mathrm{x}}_{\mathrm{is}}\right)$, where the "hat" indicates this is spending they expect to receive. Then, the probability of membership in plan $\mathrm{j}$ is $\operatorname{Pr}_{\mathrm{i}}^{\mathrm{j}}\left(\mathrm{v}_{\mathrm{i}}(\widehat{\mathbf{X}})\right)$. In the empirical applications below, consumers' predictions about what they receive will be service-specific. We assume equilibrium in the health plan market is symmetric so that in equilibrium all plans make the same decision about service-level spending and each plan has the same probability of enrolling each individual. ${ }^{14}$ Symmetry allows us to suppress plan $j$ superscripts. ${ }^{15}$

In terms of the effect of a plan's decision about spending on service s, we distinguish between what a consumer actually gets, which determines plan costs, profitability of individuals, and welfare, and what a consumer expects to get, which determines the consumer's enrollment decisions. We introduce a parameter $\sigma_{\text {is }}$ $\left(\sum_{\mathrm{s}} \sigma_{\text {is }}=1\right)$, that defines the share of total spending on service $\mathrm{s}$ allocated to individual $\mathrm{i}$ such that $\mathrm{x}_{\mathrm{is}}=\sigma_{\mathrm{is}} \mathrm{x}_{\mathrm{S}}$ where $\mathrm{x}_{\mathrm{s}}$ is the total spending on service s across all consumers, $\mathrm{x}_{\mathrm{s}}=\sum_{\mathrm{i}} \mathrm{x}_{\mathrm{is}}$. However, enrollment decisions do not depend on what consumers actually get $\left(\mathrm{x}_{\mathrm{is}}\right)$ but on what they expect to get $\left(\hat{\mathrm{x}}_{\mathrm{is}}\right)$. To deal with this we introduce a second parameter, $\widehat{\sigma}_{i s}\left(\sum_{\mathrm{s}} \widehat{\sigma}_{i s}=1\right)$, that defines the share of total spending on service $\mathrm{s}$ that individual $\mathrm{i}$ expects to be allocated to her such that $\hat{\mathrm{x}}_{\mathrm{is}}=\widehat{\sigma}_{\text {is }} \mathrm{x}_{\mathrm{S}}$. To maintain tractability, we make the assumption that $\sigma_{\text {is }}$ and $\widehat{\sigma}_{\text {is }}$ are fixed given all relevant insurer choices about total service-level allocations, $\mathbf{x}_{\mathbf{S}}$.

Given these assumptions, profits for a representative plan are

$$
\pi=\sum_{\mathrm{i}} \operatorname{Pr}_{\mathrm{i}}\left(\mathrm{v}_{\mathrm{i}}(\widehat{\mathbf{X}})\right)\left(\mathrm{r}_{\mathrm{i}}-\mathrm{x}_{\mathrm{i}}\right)
$$

\footnotetext{
14 The service-level selection case raises the possibility of a competitive equilibrium with separating contracts of the type proposed by Rothschild and Stiglitz (1976). When the equilibrium is separating, risk adjustment moves the contracts closer together, toward the pooling equilibrium, and "optimal" risk adjustment in the presence of service-level selection leads to pooling (Glazer and McGuire, 2000).

${ }^{15}$ While this assumption may seem restrictive, it is common in the economics literature on service-level selection and provides tractability to our model that allows us to derive empirically implementable methods of estimating the optimal risk adjustment payment weights. See Frank, Glazer, and McGuire (2000); Glazer and McGuire (2002); Ellis and McGuire (2007); Carey (2015); Layton, Ellis and McGuire (2015).
} 
Plans choose $\mathrm{x}_{\mathrm{S}}$ to maximize profits leading to $\mathrm{S}$ first-order conditions of the form

$$
\sum_{\mathrm{i}} \operatorname{Pr}_{\mathrm{i}}{ }^{\prime}\left(\mathrm{v}_{\mathrm{i}}(\widehat{\mathbf{X}})\right) \mathrm{v}_{\mathrm{is}}^{\prime} \widehat{\sigma}_{\mathrm{is}}\left(\mathrm{r}_{\mathrm{i}}-\mathrm{x}_{\mathrm{i}}\right)-\sum_{\mathrm{i}} \operatorname{Pr}_{\mathrm{i}}\left(\mathrm{v}_{\mathrm{i}}(\widehat{\mathbf{X}})\right) \sigma_{\text {is }}=0
$$

Denote $\alpha_{\mathrm{is}}=\operatorname{Pr}_{\mathrm{i}}{ }^{\prime}\left(\mathrm{v}_{\mathrm{i}}(\widehat{\mathbf{X}})\right) \mathrm{v}_{\mathrm{is}}^{\prime} \hat{\sigma}_{\mathrm{is}}$, so that the $\mathrm{S}$ equations become

$$
\sum_{i} \alpha_{i s}\left(r_{i}-x_{i}\right)=\frac{1}{J}
$$

where $\mathrm{J}$ is the number of plans competing in the market. ${ }^{16}$ Equation (7) implies that under profit maximization, the following S-1 equations will hold. With service $s^{\prime}$ as a numeraire, for $s \neq s^{\prime}$ :

$\sum_{\mathrm{i}} \alpha_{\mathrm{is}}\left(\mathrm{r}_{\mathrm{i}}-\mathrm{x}_{\mathrm{i}}\right)=\sum_{\mathrm{i}} \alpha_{\mathrm{is}}\left(\mathrm{r}_{\mathrm{i}}-\mathrm{x}_{\mathrm{i}}\right)$

In addition, competition implies that plans make zero profit in equilibrium:

$$
\sum_{i} r_{i}=\sum_{i} x_{i}
$$

The $\mathrm{S}$ equations in (8) and (9) describe equilibrium as a function of the risk adjusted plan payment.

Substituting in for the risk adjusted payment, the S-1 service equations can be re-written as follows:

$$
\begin{aligned}
\beta_{1} \sum_{\mathrm{i}} \mathrm{z}_{\mathrm{i} 1}\left(\alpha_{\mathrm{i} 1}-\alpha_{\mathrm{is}}\right)+\beta_{2} \sum_{\mathrm{i}} \mathrm{z}_{\mathrm{i} 2}\left(\alpha_{\mathrm{i} 1}-\alpha_{\mathrm{is}}\right)+\cdots+\beta_{\mathrm{K}} \sum_{\mathrm{i}} \mathrm{z}_{\mathrm{iK}}\left(\alpha_{\mathrm{i} 1}-\alpha_{\mathrm{is}}\right) \\
=\mathrm{x}_{1}^{\mathrm{e}} \sum_{\mathrm{i}} \sigma_{\mathrm{i} 1}\left(\alpha_{\mathrm{i} 1}-\alpha_{\mathrm{is}}\right)+\mathrm{x}_{2}^{\mathrm{e}} \sum_{\mathrm{i}} \sigma_{\mathrm{i} 2}\left(\alpha_{\mathrm{i} 1}-\alpha_{\mathrm{is}}\right)+\cdots+\mathrm{x}_{\mathrm{S}} \sum_{\mathrm{i}} \sigma_{\mathrm{iS}}\left(\alpha_{\mathrm{i} 1}-\alpha_{\mathrm{is}}\right)
\end{aligned}
$$

And the budget constraint can be written as:

$$
\sum_{\mathrm{i}} \sum_{\mathrm{k}} \beta_{\mathrm{k}} \mathrm{z}_{\mathrm{ik}}=\sum_{\mathrm{s}} \mathrm{x}_{\mathrm{s}}^{\mathrm{e}}
$$

${ }^{16}$ We get the $\frac{1}{\mathrm{~J}}$ because of the symmetric equilibrium. 
These $\mathrm{S}$ equations can, in turn, be re-written as matrices as follows:

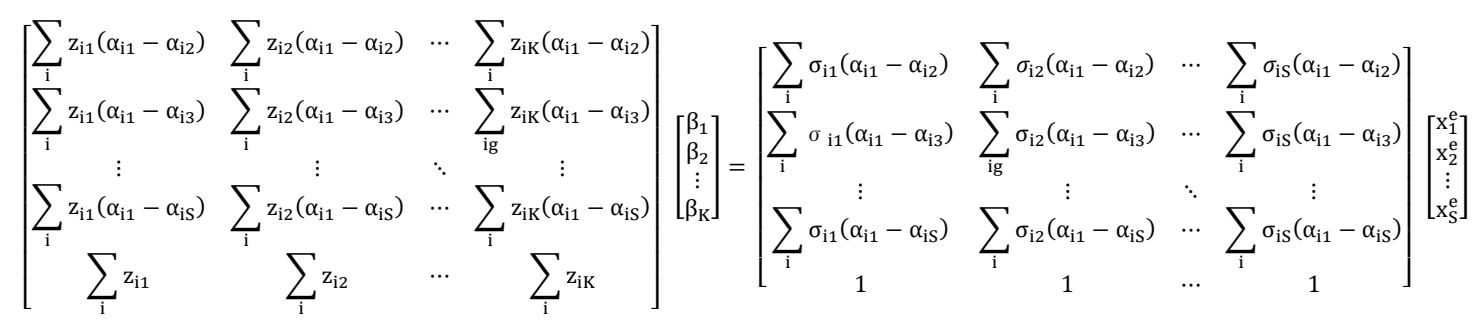

Or, in matrix notation,

$$
\Omega \beta=\Gamma x^{e}
$$

Note that given knowledge of the $\alpha$ terms, all elements of $\boldsymbol{\Omega}$ and $\boldsymbol{\Gamma}$ are either known or found in the data. For now, we will leave the $\alpha$ terms general. In the empirical section of the paper, we will make a set of assumptions that allows us to determine the $\alpha$ s from the data. Multiplying both sides by $\boldsymbol{\Gamma}^{\mathbf{- 1}}$, the equilibrium values of the group-by-service-level allocations can be expressed as a linear function of $\boldsymbol{\beta}$ and data:

$$
\Gamma^{-1} \Omega \beta=x^{e}
$$

The left hand side of this equality will be an $S \times 1$ vector where each element of the vector consists of the summation of the product of each risk adjustment payment weight times the element determined by the multiplication of $\boldsymbol{\Gamma}^{-\mathbf{1}}$ and $\boldsymbol{\Omega}$. This summation can be written as:

$$
\mathrm{x}_{\mathrm{s}}^{\mathrm{e}}=\sum_{\mathrm{k}} \beta_{\mathrm{k}} \hat{\mathrm{z}}_{\mathrm{sk}}
$$

where $\hat{z}_{\mathrm{sk}}$ is the transformed value of $\mathbf{z}_{\mathrm{k}}$ determined by the matrix product. This implies that the individuallevel equilibrium allocation of service $s$ for individual i can be written as

$$
\mathrm{x}_{\mathrm{is}}^{\mathrm{e}}=\sigma_{\mathrm{is}} \mathrm{x}_{\mathrm{s}}^{\mathrm{e}}=\sigma_{\mathrm{is}} \sum_{\mathrm{k}} \beta_{\mathrm{k}} \hat{\mathrm{z}}_{\mathrm{sk}}
$$

This can be plugged into Equation (2) above to produce an expression for the welfare loss as a function of the risk adjustment payment weights, $\beta_{\mathrm{k}}$ :

$\Delta \mathrm{W}\left(\mathbf{x}_{\mathbf{i}}^{\mathbf{e}}\right)=\frac{1}{2} \sum_{\mathrm{i}} \sum_{\mathrm{s}} \mathrm{v}_{\mathrm{is}}^{\prime \prime}\left(\sigma_{\text {is }} \sum_{\mathrm{k}} \beta_{\mathrm{k}} \hat{\mathrm{z}}_{\mathrm{sk}}-\mathrm{x}_{\mathrm{is}}^{*}\right)^{2}$ 
The task is to find the risk adjustment coefficients $\beta_{\mathrm{k}}$ that minimize (11). As noted earlier, the solution can take one of two forms depending on whether the number of services on which a plan makes decisions, $\mathrm{S}$, is greater or less than the number of risk adjustors, $\mathrm{K}$. We proceed by describing each case.

\subsection{More Risk Adjustors than Services: Constrained Least-Squares Hits First Best}

In this case, the regulator's goal for risk adjustment is to induce insurers to offer the levels of servicelevel spending that result in optimal individual allocations. Thus, the regulator desires to set the payment weights, $\beta_{\mathrm{k}}$, so that in equilibrium plans provide service level allocations $\mathrm{x}_{\mathrm{s}}^{*}$ that satisfy $\mathrm{x}_{\mathrm{i}}^{*}=\sum_{\mathrm{s}} \mathrm{x}_{\mathrm{is}}^{*}=$ $\sum_{\mathrm{s}} \sigma_{\mathrm{is}} \mathrm{x}_{\mathrm{s}}^{*}$

Equilibrium conditions ( (8') and (9') can be regarded as a system of $\mathrm{S}$ unknowns, $\mathrm{x}_{\mathbf{S}}$, with $\mathrm{K}$ variables, $\beta_{\mathrm{k}}$. When $\mathrm{S}<\mathrm{K}$, the $\beta_{\mathrm{k}}$ 's that lead plans to set service allocations efficiently in equilibrium can be characterized by substituting $x_{i}^{*}=\sum_{s} x_{i s}^{*}=\sum_{s} \sigma_{i s} x_{s}^{*}$ and $r_{i}=\sum_{k} \beta_{k} z_{i k}$ into (8') and (9') yielding the following S equations:

$\sum_{\mathrm{i}} \widehat{\sigma}_{\mathrm{is}}\left(\sum_{\mathrm{k}} \beta_{\mathrm{k}} \mathrm{z}_{\mathrm{ik}}-\sum_{\mathrm{s}} \sigma_{\mathrm{is}} \mathrm{x}_{\mathrm{s}}^{*}\right)=\sum_{\mathrm{i}} \widehat{\sigma}_{\mathrm{is}}\left(\sum_{\mathrm{k}} \beta_{\mathrm{k}} \mathrm{z}_{\mathrm{ik}}-\sum_{\mathrm{s}} \sigma_{\mathrm{is}} \mathrm{x}_{\mathrm{s}}^{*}\right)$

$\sum_{\mathrm{i}} \sum_{\mathrm{k}} \beta_{\mathrm{k}} \mathrm{z}_{\mathrm{ik}}=\sum_{\mathrm{i}} \mathrm{x}_{\mathrm{i}}^{*}$

The $S$ equations in (12) are linear in the payment weights, $\beta_{\mathrm{k}}$. Payment weights that satisfy (12) ensure that when plans can only discriminate on the basis of services the first-best allocations will be offered in equilibrium. If there are more risk adjustors than there are services (i.e., $\mathrm{K}>\mathrm{S}$ ), there will be an infinite number of combinations of payment weights that satisfy (12).

One practical method for choosing payment weights to satisfy the $\mathrm{S}$ equations is a constrained leastsquares regression, fitting a linear regression of $\mathrm{x}_{\mathrm{i}}^{*}$ on $\mathrm{z}_{\mathrm{ik}}$, with the $\mathrm{S}$ equations in (12) as constraints. This is first-best because the constraints are satisfied. The solution also has the property of maximizing fit at the person level subject to the first-best allocation. Finally, least-squares guarantees the zero-profit constraint is satisfied. We apply this method in Section 5. Note that in this case, only knowledge of $\sigma_{\text {is }}$ and $\widehat{\sigma}_{\text {is }}$ is necessary to find the optimal set of payment weights, rather than the full set of $\alpha$ terms. Again, we leave $\sigma_{\text {is }}$ and $\widehat{\sigma}_{\text {is }}$ general for now, and we will introduce the assumptions we use to produce values for $\sigma_{\text {is }}$ and $\widehat{\sigma}_{\text {is }}$ when we apply this method in Section 5. 


\subsection{More Services than Risk Adjustors: OLS with Transformed Data Minimizes Welfare Loss}

When there are more services than risk adjustors, the regulator's objective is unchanged: to induce insurers to offer the service-level allocations that minimize welfare loss. When $\mathrm{K}<\mathrm{S}$, however, the regulator has too few "instruments" to achieve first-best allocations, implying that typically only a "second-best" set of allocations can be achieved and some welfare loss will remain. This presents a more difficult problem in that the regulator needs to choose the risk adjustment payment weights that efficiently trade off the welfare losses across services.

Equation (11) shows the way forward. It is straightforward to see that a weighted least squares regression at the individual-by-service (is) level of $\mathrm{x}_{\mathrm{is}}^{*}$ on $\sigma_{\mathrm{is}} \hat{\mathrm{z}}_{\mathrm{sk}}$ where the coefficients, $\beta_{\mathrm{k}}$, are restricted to be constant across services and the individual-by-service regression weights are equal to $v_{\text {is }}^{\prime \prime}$ will generate the set of risk adjustment payment weights that minimize $\Delta \mathrm{W}\left(\mathbf{X}^{\mathbf{e}}\right)$. Making the simplifying assumption that $\mathrm{v}_{\mathrm{is}}^{\prime \prime}\left(\mathrm{x}_{\mathrm{is}}^{*}\right)=\mathrm{v}^{\prime \prime}$ for all is so that (11) can be rewritten as $\Delta \mathrm{W}\left(\mathbf{X}^{\mathbf{e}}\right)=\frac{1}{2} \mathrm{v}^{\prime \prime} \sum_{\mathrm{i}} \sum_{\mathrm{s}}\left(\sigma_{\mathrm{is}} \sum_{\mathrm{k}} \beta_{\mathrm{k}} \hat{\mathrm{z}}_{\mathrm{sk}}-\mathrm{x}_{\mathrm{is}}^{*}\right)^{2}$, the welfare-minimizing risk adjustment payment weights can be estimated by unweighted rather than weighted least squares. Thus, for the $\mathrm{S}>\mathrm{K}$ case, with a straightforward transformation of the data, researchers or regulators can estimate the efficiency-maximizing risk adjustment payment weights using either weighted or unweighted least squares.

Policymakers can often "choose" the number of risk adjustor variables so as to exceed the number of service dimensions (in order to make first-best payment weights feasible). We consider the $\mathrm{S}<\mathrm{K}$ to be the more relevant case, at least in a setting like the Netherlands with an extensive set of risk-adjustor variables. The $\mathrm{S}<\mathrm{K}$ case is the one we implement for purposes of illustration with data from the Netherlands.

\section{Demonstration of Methods Using Data from the Netherlands}

National health insurance in the Netherlands has been operating in roughly its current form since 2006. Health insurance is mandatory for all residents and based on principles of regulated competition. In 2015 about 60 plans were offered by about 25 insurers who compete on price and quality within a regulatory framework intended to promote individual affordability of health plans both for the healthy and the chronically ill. The regulatory framework includes a standard benefit package, premium rating restrictions, and risk adjustment. Open enrollment provisions ensure that plans accept every applicant.

Risk adjustment is used in the Dutch system in an attempt to weaken insurer selection incentives. The risk adjustment model provides a prediction of total annual spending for each individual; the risk 
adjustment payment from the health insurance fund to a health plan for an enrollee then equals that enrollee's predicted spending minus a fixed amount (set by the government) that must be covered by the enrollee's premium together with the loading fee.

In our empirical application we first replicate the Dutch risk adjustment model and its associated payment weights for 2015 and characterize the incentives for service-level distortion. Because we employ an explicit model of plan behavior as a function of the risk adjustment payment weights, we can derive the gaps between first-best and equilibrium spending that would occur under profit maximization and perfect competition. We next apply a constrained least-squares regression to find the payment weights that eliminate these gaps (and the welfare loss). In the remainder of this section, we briefly describe the Dutch risk adjustment model of 2015, the data available for this study, the way we operationalize "services," how we interpret the data in relation to the first-best allocations $\left(\mathrm{x}_{\mathrm{is}}^{*}\right)$, how individuals' (expected) spending on a service relates to the total spending on that service $\left(\sigma_{\text {is }}\right.$ and $\left.\widehat{\sigma}_{\text {is }}\right)$ and the measures we use to evaluate alternative risk adjustment models.

\subsection{Risk Adjustment Model 2015}

The basic Dutch risk adjustment model of 2015 includes risk adjustors based on age, gender, region, source of income, socioeconomic status, and health indicators. The latter include disease groups based on prior utilization of specific pharmaceuticals (PCGs), diagnostic groups based on prior utilization of inpatient and outpatient hospital care (DCGs), groups based on prior utilization of durable medical equipment (DMECGs) and groups based on high health care spending in multiple prior years (MYHCGs). In total, the 2015 model contains 138 indicator variables, i.e., 40 classes for an interaction between age and gender, 10 regions, 19 classes for an interaction between age and source of income, 12 classes for an interaction between age and socioeconomic status, 25 PCGs, 16 DCGs, five DMECGs, seven MYHCGs, and four classes for an interaction between age and a dummy indicating whether PCG+DCG+DMECG+MYHCG $>=1$. The model is "prospective" in that the data for the health indicators (i.e. PCG, DCG, DMECG, and MYHCG) comes from years prior to the payment year. In practice, the payment weights for these 138 indicators are estimated by a least-squares regression of medical spending on the 138 dummy variables. ${ }^{17}$ Predicted spending for an enrollee equals the sum of the product of the dummy-values and the regression coefficients for the 138 indicators. We note that in spite of years of research and model refinement, Van Kleef et al. (2015b) have shown that the current risk adjustment model undercompensates insurers for particular groups of unhealthy consumers and overcompensates them for some healthy groups, leaving incentives for risk selection.

17 The basic risk adjustment model of 2015 applies to about 83 percent of the total medical spending under the national health insurance. For the remaining 17 percent, including spending on mental health care and home care, supplemental risk adjustment models are applied. The empirical application here is for the basic model only. For technical details on the Dutch risk adjustment model, see Eijkenaar et al. (2014). 
Table 1: Population frequency and medical spending (in Euros, 2012) at aggregated levels of risk characteristics ( $\mathrm{N}=16.5$ million)

\begin{tabular}{|c|c|c|c|}
\hline & & $\begin{array}{l}\text { Population } \\
\text { frequency }\end{array}$ & $\begin{array}{c}\text { Mean } \\
\text { spending }\end{array}$ \\
\hline Male, $<65$ & & $42 \%$ & 1,207 \\
\hline Male, $>=65$ & & $8 \%$ & 4,612 \\
\hline Female, $<65$ & & $41 \%$ & 1,487 \\
\hline Female, $>=65$ & & $9 \%$ & 4,123 \\
\hline Region, clusters $1-5$ & & $50 \%$ & 1,979 \\
\hline Region, clusters 6-10 & & $50 \%$ & 1,719 \\
\hline Source of income if $18 \leq$ age $<65$ : disability benefits & & $5 \%$ & 3,817 \\
\hline Source of income if $18 \leq$ age $<65$ : social security benefits & & $2 \%$ & 2,321 \\
\hline Source of income if $18 \leq$ age $<35$ : student & & $3 \%$ & 588 \\
\hline Source of income if $18 \leq$ age $<65$ : self-employment & & $4 \%$ & 1,012 \\
\hline Source of income if $18 \leq$ age $<65$ : other (e.g. employment) & & $48 \%$ & 1,282 \\
\hline Socioeconomic status, street address with $>15$ residents & & $1 \%$ & 4,507 \\
\hline Socioeconomic status, income deciles 1-3 & & $30 \%$ & 1,842 \\
\hline Socioeconomic status, income deciles $4-7$ & & $40 \%$ & 1,869 \\
\hline Socioeconomic status, income deciles $8-10$ & & $30 \%$ & 1,721 \\
\hline \multirow[t]{2}{*}{ Pharmacy-based Cost Group (PCG) } & No & $82 \%$ & 1,212 \\
\hline & Yes & $18 \%$ & 4,751 \\
\hline \multirow[t]{2}{*}{ Diagnoses-based Cost Group (DCG) } & No & $91 \%$ & 1,353 \\
\hline & Yes & $9 \%$ & 6,855 \\
\hline \multirow[t]{2}{*}{ Durable Medical Equipment Cost Group (DMECG) } & No & $99 \%$ & 1,772 \\
\hline & Yes & $1 \%$ & 10,933 \\
\hline \multirow[t]{2}{*}{ Multiple-year High Cost Group (MYHCG) } & No & $94 \%$ & 1,378 \\
\hline & Yes & $6 \%$ & 9,536 \\
\hline \multirow[t]{2}{*}{ PCG, DCG, DMECG and/or MYHCG } & No & $77 \%$ & 984 \\
\hline & Yes & $23 \%$ & 4,784 \\
\hline Total population & & $100 \%$ & 1,848 \\
\hline
\end{tabular}

Note: the risk adjustor variable "Source of income" only applies to people in the age of 18 to 65. 


\subsection{Data}

Our data include individual-level health care spending in 2012 and risk indicators for the Dutch population of approximately 16.5 million. The indicators for age/gender, region, source of income and socioeconomic status are based on information from 2012, whereas the PCGs, DCGs, DMECGs and MYHCGs are based on information from 2009-2011. Table 1 provides the population frequency of some risk indicators and the distribution of medical spending. Overall average medical spending equals 1,848 Euro per person per year. Not surprisingly, average spending is relatively high for people age 65 or older, those receiving a disability benefit, people living at an address with more than 15 residents (a proxy for being in an institution for long-term care) and those in a PCG, DCG, DMECG and/or MYHCG. Nearly 23 percent of the population is classified by at least one PCG, DCG, DMECG or MYHCG.

\subsection{Defining Services}

In the Dutch data used for risk adjustment medical spending is categorized according to ten types of medical services, with information on spending per person shown in Table $2 .{ }^{18}$ Hospital care (which includes both facility and professional in-hospital costs) is by far the largest category at 61 percent, followed by pharmaceuticals (14 percent) and primary care (8 percent). Not surprisingly, for each service the distribution of spending is skewed. While these ten services are plausible levels of discrimination available to plans through their provider contracting decisions, ultimately, implementation of our methods may require a more refined categorization when health plans are believed to discriminate within some of these categories. For example, the large category of hospital care might be disaggregated into particular services, such as care for patients with cancer or kidney failure, and other services. However, in the data available to us, we are unable to disaggregate services beyond the ten shown in Table 2.

\subsection{Defining First-Best Spending}

The empirical methods for deriving the optimal risk adjustment payment weights described in Section 3 call for specification of the efficient spending levels, denoted $\mathrm{x}_{\mathrm{is}}^{*}$. The data available, however, are the actual spending patterns by person and service under the risk adjustment model and corresponding weights applicable at the time, which may or may not be regarded as optimal. Before we discuss our approach to this issue, it is worth noting that the statistics and simulations applied in existing approaches to risk adjustment implicitly treat the existing patterns in the data as the target for desired spending. ${ }^{19}$

18 This categorization is given in the data available to estimate risk adjustment payment weights. Data used by the Ministry of Health for this purpose is a compilation of data feeds from health plans via an intermediary institution that is required to submit data in a certain format.

${ }_{19}$ The commonly used R-squared measures "fit" of a payment model in relation to the data on spending used to estimate the model. A "predictive ratio" computed to check revenues in relation to costs for groups of interest uses observed spending as the standard against which to assess payments for a particular group. See, for example, Kautter et 
Table 2 Average spending per service category (in Euros, 2012)

\begin{tabular}{|c|c|c|c|c|c|}
\hline & Mean & Std Dev & 75th Pctl & 95th Pctl & $\begin{array}{r}\text { Share of } \\
\text { total } \\
\text { spending }\end{array}$ \\
\hline Hospital care & 1132 & 5612 & 608 & 4779 & $61 \%$ \\
\hline Pharmaceuticals & 267 & 1309 & 186 & 1163 & $14 \%$ \\
\hline Primary care & 139 & 148 & 160 & 315 & $8 \%$ \\
\hline Durable medical equipment & 91 & 581 & 2 & 368 & $5 \%$ \\
\hline Geriatric physical therapy & 46 & 1145 & 0 & 0 & $3 \%$ \\
\hline Dental care (18-) & 44 & 238 & 2 & 197 & $2 \%$ \\
\hline Paramedical care & 42 & 242 & 0 & 127 & $2 \%$ \\
\hline Sick transport & 35 & 331 & 0 & 8 & $2 \%$ \\
\hline Obstetrics and maternity care & 29 & 283 & 0 & 0 & $2 \%$ \\
\hline Other a & 23 & 503 & 0 & 27 & $1 \%$ \\
\hline Total & 1848 & 6595 & 1392 & 7342 & $100 \%$ \\
\hline
\end{tabular}

a Including very small categories of spending such as 'ambulatory care for people with auditive or visual impairments'.

Highlighting the implicit assumption about the optimality of current spending patterns exposes a logical problem with risk adjustment methodology. If the current spending pattern is optimal, and it is also an equilibrium response to the current payment system, why change the payment system? This status-quo logic would lead to the obviously incorrect conclusion that the payment system should never be changed. In order to justify a change in the payment system, the existing pattern of expenditure must be either not an equilibrium or not optimal (or both). ${ }^{20}$ We first drop one and then both assumptions. First, we drop the equilibrium assumption; we assume the existing pattern is the desired pattern but not an equilibrium. We then calculate equilibrium spending by deriving the implications of profit maximization as described above.

al. 2014) for evaluation of the U.S. federal risk adjustment model or Van Kleef et al. (2015a) for evaluation of the Dutch model according to fit against the existing data and over and undercompensation by group against costs observed in the data.

${ }^{20}$ Sometimes, risk adjustment models are estimated using data on spending patterns from a different setting than the market where the risk adjustment policy will be estimated. This is true in the U.S. for Medicare and Medicaid, where risk adjustment models are estimated using data from the fee-for-service programs but risk adjusted payments are used only in the Medicare Advantage or Medicaid Managed care programs, and in the state and federal Health Insurance Marketplaces, where models are estimated using data from employer-sponsored insurance (ESI) plans but risk adjusted payments are used to pay Marketplace plans. In these settings, it could be the case that the observed spending patterns are both optimal and in equilibrium in the context where the data come from (FFS or ESI), but they represent optimal but not equilibrium spending in the context where risk adjustment is being used. In these particular settings, optimal spending may be similar while equilibrium spending is different due to the fact that selection incentives affect equilibrium allocations in the Marketplaces, Medicare Advantage, and Medicaid Managed Care but not in FFS or ESI. 
Second, we drop both assumptions and study the case in which the patterns in the data are neither efficient nor an equilibrium. Equilibrium we can calculate by applying conditions for profit maximization. The need to specify optimal patterns of spending led us to an insight. If we believe the optimal service-level allocations, $\mathrm{x}_{\mathrm{S}}^{*}$, differ from the observed service-level allocations, before estimating or evaluating a risk adjustment model we should first alter the observed allocations so that they reflect the desired rather than the observed distribution of spending across services. Suppose, for example, that there were a consensus that the health care system should spend more on primary care for persons with a set of chronic illnesses, possibly with the idea of offsetting some institutional care. In terms of plan payment and risk adjustment, we then want to derive the payment weights that "support the spending we want." The implication for risk adjustment would then be: transform the data in the ways that reflect what we want to happen; then estimate the payment weights that lead to this as an equilibrium.

For the basic empirical analyses in Section 5 we follow conventional practice of risk adjustment and estimate the payment weights based on the data "as is," thereby invoking the implicit assumption that the observed patterns of spending are, in fact, optimal. In Section 6 below, we illustrate how this assumption can be relaxed by estimating payment weights "for the system we want rather than the system we have" by transforming the data before estimation of the payment weights.

\subsection{Assumptions Regarding $\sigma_{\text {is }}$ and $\widehat{\sigma}_{\text {is }}$}

In order to apply the methods described in Section 3 to derive the optimal set of risk adjustment payment weights in the case where $\mathrm{S}<\mathrm{K}$, we need to know the values of $\sigma_{\text {is }}$ and $\widehat{\sigma}_{\text {is }}$. As discussed above, we assume that $\sigma_{\text {is }}$ is fixed across all relevant service-level allocations and use the observed share in the data to determine what an individual actually gets in terms of a share of the total service-level allocation: $\sigma_{\text {is }}=\frac{x_{i s}}{x_{s}}$, $\sum_{\mathrm{i}} \sigma_{\mathrm{is}}=1$. For example, if we observe that an individual receives $\$ 100$ of diabetes-related care in the claims data and that the total allocation of diabetes-related care across all individuals is $\$ 10,000$, then $\sigma_{\text {is }}=\frac{100}{10,000}=$ 0.01 . We then assume that if the plan chooses to increase spending on diabetes-related care overall by $\$ 5,000$ to $\$ 15,000$, the individual's allocation of diabetes care will increase in proportion such that her new allocation of diabetes-related care will be $\mathrm{x}_{\mathrm{is}}=\sigma_{\mathrm{is}} \mathrm{x}_{\mathrm{S}}=(0.01)(15,000)=\$ 150$. Thus, given $\sigma_{\text {is }}$ we can determine what an individual gets as a function of the plan's decision about the total service-level allocation, $\mathbf{x}_{\mathbf{s}}$.

In addition to the actual allocation of spending across individuals, our method also requires each consumer's expected allocation, $\hat{\mathrm{x}}_{\text {is }}$. In the empirical section, we determine $\hat{\mathrm{x}}_{\mathrm{is}}$ in two steps. First, we estimate a prediction equation for each service, under the assumption that individuals can use information about past 
spending to predict future spending on a service. ${ }^{21}$ In these prediction equations we require the sum of predicted spending to be equal to the sum of observed spending, i.e. $\sum_{\mathrm{i}} \hat{\mathrm{x}}_{\mathrm{is}}=\mathrm{x}_{\mathrm{S}}$. The empirical model for $\hat{\mathrm{x}}_{\mathrm{is}}$ then determines the fixed allocation rule that distributes plan-level spending on service $\mathrm{s}, \mathrm{x}_{\mathrm{s}}$, to individuals. Specifically, define $\widehat{\sigma}_{\text {is }}=\frac{\widehat{x}_{\text {is }}}{\mathrm{x}_{\mathrm{s}}}$ at the observed spending levels. In a second step, with $\widehat{\sigma}_{\text {is }}$ fixed, we can state how $\hat{\mathrm{x}}_{\mathrm{is}}$ varies with different levels of $\mathrm{x}_{\mathbf{s}} \cdot{ }^{22}$ For example, if the individual from the previous example expects $\$ 500$ spending on diabetes-related care then $\widehat{\sigma}_{i s}=\frac{500}{10,000}=0.05$. If the plan chooses to increase spending on diabetes-related care overall by $\$ 5,000$ to $\$ 15,000$, the individual's expected allocation of diabetes care will increase in proportion such that $\hat{\mathrm{x}}_{\mathrm{is}}=\widehat{\sigma}_{\text {is }} \mathrm{x}_{\mathrm{S}}=(0.05)(15,000)=\$ 750$. Thus, given a $\widehat{\sigma}_{\text {is }}$ we can determine what an individual expects to get as a function of the plan's decision about the total service-level allocation, $\mathbf{x}_{\mathbf{s}}$.

\subsection{Measures}

We use several measures to compare conventional risk adjustment and the constrained regression method outlined in Section 3.4. Some of these measures are (with minor modifications) taken from the previous literature on selection and risk adjustment. Others follow from our model of plan profit maximization. All of these measures are model-driven and motivated by efficiency. We also report the conventional R-squared.

\subsubsection{Equilibrium vs. Optimal Spending Allocations}

Our model of consumer and plan behavior allows us to go beyond the incentives to the implications for equilibrium spending, and to compare this to the spending patterns specified as optimal, but this requires an additional assumption. Recall that (10) provides the equilibrium service-level allocations as a linear function of the risk adjustment payment weights, $\beta_{\mathrm{k}}$ :

$$
\Gamma^{-1} \Omega \beta=x^{e}
$$

As discussed in Section 3, this expression shows that given knowledge of $\alpha_{\text {is }}$ equilibrium service-level allocations can be calculated from the data. Recall that $\alpha_{\text {is }}=\operatorname{Pr}_{\mathrm{i}}{ }^{\prime}\left(\mathrm{v}_{\mathrm{i}}(\widehat{\mathbf{X}})\right) \mathrm{v}_{\mathrm{is}}^{\prime} \hat{\sigma}_{\text {is }}$. In order to illustrate the implementation of the methods we describe above, we make the assumption that $\operatorname{Pr}_{\mathrm{i}}{ }^{\prime}\left(\mathrm{v}_{\mathrm{i}}(\widehat{\mathbf{X}})\right) \mathrm{v}_{\mathrm{is}}^{\prime}=\alpha_{\mathrm{is}}=\alpha$

\footnotetext{
${ }^{21}$ We explain how we model $\hat{\mathrm{x}}_{\mathrm{is}}$ in more detail in Section 5.

22 Under this conceptualization of expected spending, we assume that each consumer observes the full set of expost spending allocations assigned to each individual and service. Thus, they observe the true allocation rules, $\sigma_{\text {is }}$. The uncertainty enters because each individual does not know ex ante which line of the contract $\mathbf{X}$ from Section 3.1, and thus which allocation rule, applies to them (i.e., they don't know which i they are). Under the specification of $\widehat{\sigma}_{\text {is }}$ outlined above, we effectively group individuals into "types" based on demographics and prior spending, and we assume that an individual's expectation of the allocation they will receive under contract $\widehat{\sigma}_{\text {is }}$ is the rational expectation, or the average of the allocations assigned to individuals of the same type.
} 
for all individuals and services. ${ }^{23}$ It is straightforward to show that given this assumption, $\alpha$ drops out of the formula for $\mathbf{x}^{\mathbf{e}}$ allowing us to avoid specifying a value. Given our assumption that $\widehat{\sigma}_{\text {is }}=\frac{\hat{\mathrm{x}}_{\text {is }}}{\mathrm{x}_{\mathrm{s}}}$, where $\hat{\mathrm{x}}_{\text {is }}$ and $\mathbf{x}_{\mathbf{S}}$ are the expected individual-by-service- and actual service-level allocations, the elements of $\boldsymbol{\Gamma}^{\mathbf{- 1}}$ and $\boldsymbol{\Omega}$ are all observable in the data except for $\hat{\mathrm{x}}_{\text {is }}$. In order to determine $\hat{\mathrm{x}}_{\text {is }}$ we estimated an individual level least-squares regression with actual spending for service $\mathrm{s}$ as the dependent variable and the following two independent variables: prior-year spending on service s (continuously) and the sum of prior-year spending on all services other than s (also continuously). ${ }^{24,25}$ Finally, for a given payment system the full vector of risk adjustment weights, $\boldsymbol{\beta}$, is also known. This implies that for any payment system, we can calculate the full vector of service-level equilibrium allocations, $\mathbf{x}^{\mathbf{e}}$.

In Section 5, we form the matrices, $\boldsymbol{\Gamma}^{\mathbf{- 1}}, \boldsymbol{\Omega}$, and $\boldsymbol{\beta}$, and apply them to solve for $\mathbf{x}^{\mathbf{e}}$. We compare those allocations for different sets of payment weights to illustrate how patterns of equilibrium service-level spending compare across different risk adjustment models.

\subsubsection{Welfare Loss Metric}

The expression for welfare loss in (11) provides a natural metric to use to compare risk adjustment models:

$\Delta \mathrm{W}\left(\mathbf{x}_{\mathbf{i}}^{\mathbf{e}}\right)=\frac{1}{2} \sum_{\mathrm{i}} \sum_{\mathrm{s}} \mathrm{v}_{\mathrm{is}}^{\prime \prime}\left(\sigma_{\mathrm{is}} \sum_{\mathrm{k}} \beta_{\mathrm{k}} \hat{\mathrm{z}}_{\mathrm{sk}}-\mathrm{x}_{\mathrm{is}}^{*}\right)^{2}$

If we assume that $\mathrm{v}_{\mathrm{is}}^{\prime \prime}=\mathrm{v}^{\prime \prime}$ for all $\mathrm{i}$ and $\mathrm{s}$ (the same assumption necessary for interpretation of an R-squared as a welfare measure in the context of individual-level discrimination) this can be re-written as

$\Delta \mathrm{W}\left(\mathbf{x}_{\mathbf{i}}^{\mathbf{e}}\right)=\frac{1}{2} \mathrm{v}^{\prime \prime} \sum_{\mathrm{i}} \sum_{\mathrm{s}}\left(\sigma_{\mathrm{is}} \sum_{\mathrm{k}} \beta_{\mathrm{k}} \widehat{\mathrm{z}}_{\mathrm{sk}}-\mathrm{x}_{\mathrm{is}}^{*}\right)^{2}$

${ }^{23}$ This assumption follows from two underlying assumptions: (1) that an individual's utility from enrolling in plan $j$ is $\mathrm{v}_{\mathrm{is}}^{\mathrm{j}}=\sum_{\mathrm{s}} \mathrm{v}_{\mathrm{is}}\left(\mathrm{x}_{\mathrm{is}}^{\mathrm{j}}\right)+\epsilon_{\mathrm{i}}^{\mathrm{j}}$ and $\epsilon_{\mathrm{i}}^{\mathrm{j}}$ follows a uniform distribution, so that $\operatorname{Pr}_{\mathrm{i}}{ }^{\prime}\left(\mathrm{v}_{\mathrm{is}}\left(\mathbf{x}_{\mathbf{i}}\right)\right)$ is equal to a constant and (2) that

$\mathrm{v}_{\mathrm{is}}^{\prime}=1$ across individuals and services. The idea is that for each service consumers respond about equally in plan choice to changes in allocations of spending. Given data on $\frac{\partial \mathrm{Pr}_{\mathrm{i}}}{\partial \mathrm{x}_{\mathrm{is}}}$ (which we do not have), this assumption can be relaxed and the actual value of the derivative can be used instead.

${ }^{24}$ One exception was "obstetrics and maternity care" for which we estimated a model with just age and gender as independent variables since (not surprisingly) prior-year spending had hardly any explanatory power.

${ }^{25} \mathrm{We}$ found the following R-squared values for the ten regression models: 0.11 for hospital care, 0.71 for pharmaceuticals, 0.19 for primary care, 0.47 for durable medical equipment, 0.02 for geriatric physical therapy, 0.03 for dental care (18-), 0.38 for paramedical care, 0.16 for sick transport, 0.09 for obstetrics and maternity care and 0.01 for other care. Additional explanatory variables (such as the morbidity classes in the Dutch risk adjustment model) did not result in substantial improvement of explanatory power. 
Note that this measure relies on the solution for equilibrium spending by service derived in the previous section. Expression (11) for welfare loss is non-negative with an upper bound that depends on the covered population, the number of services, as well as the properties of the risk adjustment system in terms of risk adjustor variables and their coefficients. In order to compare alternative risk adjustment payment weights, and to put our measure in a form analogous to the familiar R-squared statistic, we measure the efficiency properties of a given set of payment weights in terms of the improvement gained over a payment system with no risk adjustment, that is, when a plan is paid the simple population average for each member. In this case

$$
\boldsymbol{\Omega}=\mathbf{\Omega}^{\text {nora }}\left[\begin{array}{c}
\sum_{\mathrm{i}}\left(\widehat{\sigma}_{\mathrm{i} 1}-\widehat{\sigma}_{\mathrm{i} 2}\right) \\
\sum_{\mathrm{i}}\left(\widehat{\sigma}_{\mathrm{i} 1}-\widehat{\sigma}_{\mathrm{i} 3}\right) \\
\vdots \\
\sum_{\mathrm{i}} \mathrm{z}_{\mathrm{i} 1}\left(\widehat{\sigma}_{\mathrm{i} 1}-\widehat{\sigma}_{\mathrm{iS}}\right) \\
\sum_{\mathrm{i}} \mathrm{z}_{\mathrm{i} 1}
\end{array}\right] \quad \boldsymbol{\beta}=\boldsymbol{\beta}^{\text {nora }}=[\mathbf{1}]
$$

Thus, the equilibrium service-level allocations, $\mathbf{x}^{\mathbf{e}, \text { nora }}$, can be expressed as

$$
\Gamma^{-1} \Omega^{\text {nora }}=\mathbf{x}^{\mathbf{e}, \text { nora }}
$$

Now, define $\hat{z}_{S}^{\text {nora }}$ such that $\mathrm{x}_{\mathrm{S}}^{\mathrm{e}, \mathrm{nora}}=\hat{\mathrm{z}}_{\mathrm{S}}$. Then, we can write the welfare loss for the "no risk adjustment" case as

$$
\Delta \mathrm{W}\left(\mathbf{x}_{\mathbf{i}}^{\mathbf{e}}\right)=\frac{1}{2} \mathrm{v}^{\prime \prime} \sum_{\mathrm{i}} \sum_{\mathrm{s}}\left(\sigma_{\mathrm{is}} \hat{\mathrm{z}}_{\mathrm{s}}^{\text {nora }}-\mathrm{x}_{\mathrm{is}}^{*}\right)^{2}
$$

We thus define our loss measure as:

$$
\phi=1-\frac{\frac{1}{2} \mathrm{v}^{\prime \prime} \sum_{\mathrm{i}} \sum_{\mathrm{s}}\left(\sigma_{\mathrm{is}} \sum_{\mathrm{k}} \beta_{\mathrm{k}} \hat{\mathrm{z}}_{\mathrm{sk}}-\mathrm{x}_{\mathrm{is}}^{*}\right)^{2}}{\frac{1}{2} \mathrm{v}^{\prime \prime} \sum_{\mathrm{i}} \sum_{\mathrm{s}}\left(\sigma_{\mathrm{is}} \hat{\mathrm{z}}_{\mathrm{s}}^{\text {nora }}-\mathrm{x}_{\mathrm{is}}^{*}\right)^{2}}=1-\frac{\sum_{\mathrm{i}} \sum_{\mathrm{s}}\left(\sigma_{\mathrm{is}} \sum_{\mathrm{k}} \beta_{\mathrm{k}} \hat{\mathrm{z}}_{\mathrm{sk}}-\mathrm{x}_{\mathrm{is}}^{*}\right)^{2}}{\sum_{\mathrm{i}} \sum_{\mathrm{s}}\left(\sigma_{\mathrm{is}} \hat{\mathrm{z}}_{\mathrm{s}}^{\text {nora }}-\mathrm{x}_{\mathrm{is}}^{*}\right)^{2}}
$$

Note that $\phi$ mimics an R-squared statistic. $\phi$ will equal zero in the extreme case of no risk adjustment and it will equal one when the welfare loss is fully eliminated.

\subsubsection{Components of Selection Incentives: Predictability and Predictiveness}

A profit-maximizing health plan has incentives to skimp on services that are predictable by enrollees and predictive of financial losses. As shown by Ellis and McGuire (2007), profit maximization implies that 
the combination of measures of predictability and predictiveness is a summary index for service-level selection incentives. Our model produces a similar result. Equation (12) shows that an insurer's incentive to ration a service is described by the following expression:

$$
\sum_{\mathrm{i}} \widehat{\sigma}_{\mathrm{is}}\left(\sum_{\mathrm{k}} \beta_{\mathrm{k}} \mathrm{z}_{\mathrm{ik}}-\sum_{\mathrm{s}} \sigma_{\mathrm{is}} \mathrm{x}_{\mathrm{s}}^{*}\right)
$$

This expression can be written as:

$$
\sum_{\mathrm{i}}\left[\frac{\widehat{\sigma}_{\mathrm{is}}}{\sigma_{\mathrm{is}}}\right]\left[\sigma_{\text {is }}\left(\sum_{\mathrm{k}} \beta_{\mathrm{k}} z_{\mathrm{ik}}-\sum_{\mathrm{s}} \sigma_{\text {is }} \mathrm{x}_{\mathrm{s}}^{*}\right)\right]
$$

This expression can be divided into two components, one representing "predictability" and the other representing "predictiveness." We operationalize these two components as follows. The first component, $\frac{\widehat{\sigma}_{\text {is }}}{\sigma_{\text {is }}}$, captures the "predictability" of the service. Predictability measures how well consumers can anticipate what spending, $\hat{\mathrm{x}}_{\mathrm{is}}$, they will receive, given the plan's decision about total spending on a service, $\mathrm{x}_{\mathrm{s}}$. We follow Ellis and McGuire (2007) and use the correlation between $\sigma_{\text {is }}$ and $\widehat{\sigma}_{\text {is }}$ as a measure of predictability:

$$
\text { Predictability }_{\mathrm{s}}=\operatorname{Corr}\left(\sigma_{\text {is }}, \widehat{\sigma}_{\text {is }}\right)
$$

Recall that $\sigma_{\text {is }}$ represents the portion of the total spending allocated to service $s$ that is actually allocated to individual i. $\widehat{\sigma}_{\text {is }}$, on the other hand, represents the portion of the total spending allocated to service $\mathrm{s}$ that individual $i$ expects to be allocated to her. Given these definitions of $\sigma_{\text {is }}$ and $\widehat{\sigma}_{\text {is }}$, this correlation is the correlation between an individual's actual spending on a service and her expected spending on that service. If the service is strongly (weakly) predictable, the correlation between actual and expected spending will be high (low). Predictability does not vary across payment systems since the expected portion of spending $\left(\widehat{\sigma}_{\text {is }}\right)$ as well as the actual portion of spending $\left(\sigma_{\text {is }}\right)$ spending are independent of payment weights (see Section 3 ).

The second component, $\sigma_{\mathrm{is}}\left(\sum_{\mathrm{k}} \beta_{\mathrm{k}} \mathrm{z}_{\mathrm{ik}}-\sum_{\mathrm{s}} \sigma_{\mathrm{is}} \mathrm{x}_{\mathrm{s}}^{*}\right)$, represents the "predictiveness" of the service. Predictiveness is related to the correlation between an individual's share of spending on a service and her overall profitability to the plan. We find it more intuitive to depict predictiveness in terms of the correlation of service-level spending with losses rather than profits. We again follow Ellis and McGuire (2007) and use this correlation as our measure of predictiveness:

$$
\text { Predictiveness }_{\mathrm{s}}=\operatorname{Corr}\left(\sigma_{\mathrm{is}}, \sum_{\mathrm{s}} \sigma_{\mathrm{is}} \mathrm{x}_{\mathrm{s}}^{*}-\sum_{\mathrm{k}} \beta_{\mathrm{k}} \mathrm{z}_{\mathrm{ik}}\right)
$$


In contrast to predictability, predictiveness will vary as risk adjustment payment weights vary. We report our measures of predictability and predictiveness in Section 5 in order to show that our new method for estimating risk adjustment payment weights improves performance not only on the metrics derived from our model but also on metrics derived in the previous literature on service-level selection.

\section{Empirical Methods and Results}

This section presents our illustrative demonstration of the potential practical implementation of the methods and measures derived in Sections 3 and 4. We estimate two sets of payment weights using data on the entire Dutch population ( $N=16.5$ million). For each set of weights, we use the same set of 138 risk adjustor variables but different estimation methods. The first payment weight estimates replicate the conventional estimation method used to derive payment weights in the Dutch risk adjustment model for 2015: a leastsquares regression (OLS) of total spending on the 138 risk indicators plus an intercept. ${ }^{26}$ The coefficient estimates for this model can be found in the Appendix.

The second set of weights is estimated using the methods we developed in Section 3. Recall that when plans discriminate at the service level, a set of equilibrium equations describes plan allocation decisions as a function of the risk adjustment payment weights. Substituting the efficient level of spending in these equations transforms them into a system of $\mathrm{S}$ equations and $\mathrm{K}$ unknowns. Because $\mathrm{S}<\mathrm{K}$, there exist an infinite number of solutions to this system of equations, all maximizing the social welfare function. We use a constrained OLS regression to find the solution that maximizes the conventional R-squared conditional on achieving the optimal service-level allocations. ${ }^{27}$ Coefficient estimates for this model can also be found in the Appendix.

The two sets of payment weights differ in important and interesting ways. Compared to the base set of weights, the constrained regression method leads to an increase of mean predicted spending for people 65 or older and those in a PCG, DCG, DMECG and/or MYHCG (i.e., those with a chronic condition) and a

\footnotetext{
${ }^{26}$ The only difference between the model we estimate here and the Dutch risk adjustment model is that the actual model has no intercept and includes a set of constraints to make sure that for age/gender categories the product of payment weights and prevalence equals the average per person spending in the population and that for each of the other seven sets of risk adjuster variables (regional categories, SES categories, categories based on source of income, PCGs, DCGs, DMECGs and MYHCGs) this product also equals zero.

${ }_{27}$ Though this solution requires an additional data step to construct the constraints, the constrained regression itself can be easily implemented in SAS, using the RESTRICT option in PROC REG. In order to use equation (8) as a constraint on the estimated betas (8) can be split into the following components:

$\sum_{\mathrm{k}} \beta_{\mathrm{k}} \sum_{\mathrm{i}} \widehat{\sigma}_{\mathrm{is}} \mathrm{z}_{\mathrm{ik}}-\sum_{\mathrm{i}} \widehat{\sigma}_{\mathrm{is}} \sum_{\mathrm{s}} \sigma_{\mathrm{is}} \mathrm{x}_{\mathrm{s}}^{*}=\sum_{\mathrm{k}} \beta_{\mathrm{k}} \sum_{\mathrm{i}} \widehat{\sigma}_{\mathrm{is}} \mathrm{z}_{\mathrm{ik}}-\sum_{\mathrm{i}} \widehat{\sigma}_{\mathrm{is}} \sum_{\mathrm{s}} \sigma_{\mathrm{is}} \mathrm{x}_{\mathrm{s}}^{*}$. All components (except for the betas) can be found by making initial passes through the data. See Van Kleef et al. (2015) for more explanation of the construction of the constraints. In fact, this constraint equalizes the selection index (Figure 3) across services.
} 
Figure 1: Average Payments for Enrollees with Selected "Healthy" and "Sick" Indicators in Two Models

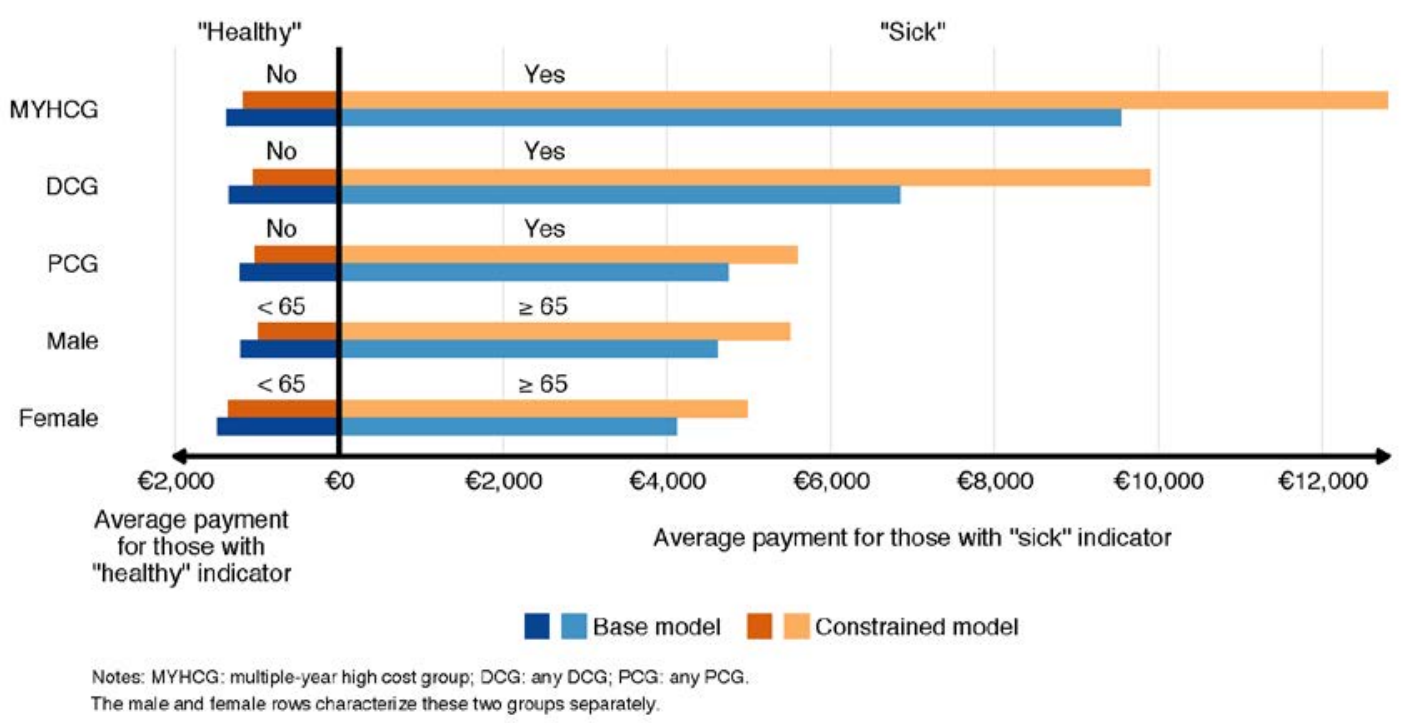

decrease of mean predicted spending for the complementary groups. This can be seen in Figure $1 .{ }^{28}$ The figure shows the payments for 5 stratifications of the population. For each stratification, the average payment for the healthier of the two groups is shown on the left while the average payment for the sicker group is shown on the right. The figure shows average payments under the conventional Dutch risk adjustment model (orange bars) and the constrained model (blue bars). Generally, the constrained model tends to encourage more spending on sick people. This is consistent with Glazer and McGuire's (2000) analytic result that an optimal risk adjustment model will "overpay" (i.e. pay more than average spending) for individuals with a "sick signal" and underpay for individuals with a "healthy" signal. Nonetheless, the correlation in individuallevel predicted spending between the base model and the constrained model is high at 0.94 . This suggests that at least in this illustrative application, shifting payments to sicker people in the way suggested by the constrained regression would not be a highly disruptive change with respect to the flow of funds across insurers.

Table 3 compares the two models in terms of R-squared and our welfare loss measure $\phi$. Compared to the base model, the constrained model led to a drop in R-squared, which of course must be true since the constraints will bind. However, as we showed in Section 3, the R-squared is the appropriate measure of payment system performance only in a very special case. In terms of our alternative welfare loss measure, the constrained model completely eliminates the welfare loss remaining from the base model. This also must be true, given that the estimation method used for the constrained model can fully solve the resource allocation problem with only ten service-level spending targets and 138 risk adjustor variables. From these results we

${ }^{28}$ For all empirical measures presented in this paper, we calculated confidence intervals using bootstrapping. Since the confidence intervals turned out to be extremely tight we decided not to present them. 
Table 3. R-squared and welfare loss measure for two models in relation to no risk adjustment

\begin{tabular}{lccc}
\hline Measure & $\begin{array}{c}\text { No risk } \\
\text { adjustment }\end{array}$ & Base model & Constrained model \\
\hline R-squared & 0,000 & 0,226 & 0,129 \\
\hline Welfare loss measure $(\phi)$ & 0,000 & 0,828 & 1,000 \\
\hline
\end{tabular}

can conclude that if the ten services we use here to illustrate these methods and measures were the relevant dimensions on which plans could discriminate, the constrained model clearly outperforms the base model.

\subsection{Equilibrium Service-level Allocations Implied by Plan Profit Maximization}

In addition to a measure of overall payment system performance, our model from Section 3 allows us to derive equilibrium service-level allocations implied by the different payment models. We interpret our predictions about service-level allocations under the alternative set of risk adjustment payment weights as

indicating the general pattern of mismatches between equilibrium spending and optimal spending as well as the direction in which profit maximization is pushing health plans to distort service-level spending. The gaps between the "optimal" and "equilibrium" allocations we present below should be interpreted as rough measures of the force of the distortionary incentive.

Figure 2 presents the equilibrium service-level allocations under the two payment models, the conventional Dutch model (blue bars) and the constrained model (orange bars) along with the optimal level of service-level spending (purple bars), which, as we explained above, we assume in this section to be equal to the spending observed in the data. All allocations are presented as a percent of total spending, which is constrained to be constant across payment models. The purple bars show that the optimal (and observed) level of spending on primary care is less than $10 \%$. Our model, however, implies that under the conventional Dutch risk adjustment model, plans have incentives to drive the level of spending on primary care above $30 \%$. This suggests that plans are incentivized to distort substantial resources toward primary care and away from other services as they compete for low-cost (and profitable) enrollees. ${ }^{29}$ This distortion is largely due to

${ }^{29}$ One might note that this finding is does not seem to hold in real health insurance markets. Typically, policymakers and researchers argue that primary care is underprovided relative to other services. We make two comments regarding this seeming discrepancy. First, our model obviously paints an incomplete picture of an insurer's choice of service-level allocations. While our model captures insurer incentives related to adverse selection appropriately, it does not account for incentives related to other factors such as the short-term nature of many insurance contracts. Second, much of the discussion of the underprovision of primary care comes from the United States, where the vast majority of individuals get health insurance either through their employer or through the FFS Medicare program. In both of these settings, insurers face no or very weak selection incentives, implying that the implications of our model should not be compared to empirical facts in those settings. Instead, our model should have implications for insurer behavior in markets where selection is more prevalent such as the Medicare Advantage program, the state and federal Health Insurance Marketplaces, and state Medicaid Managed Care programs. 
Figure 2: Equilibrium Service Level Allocation

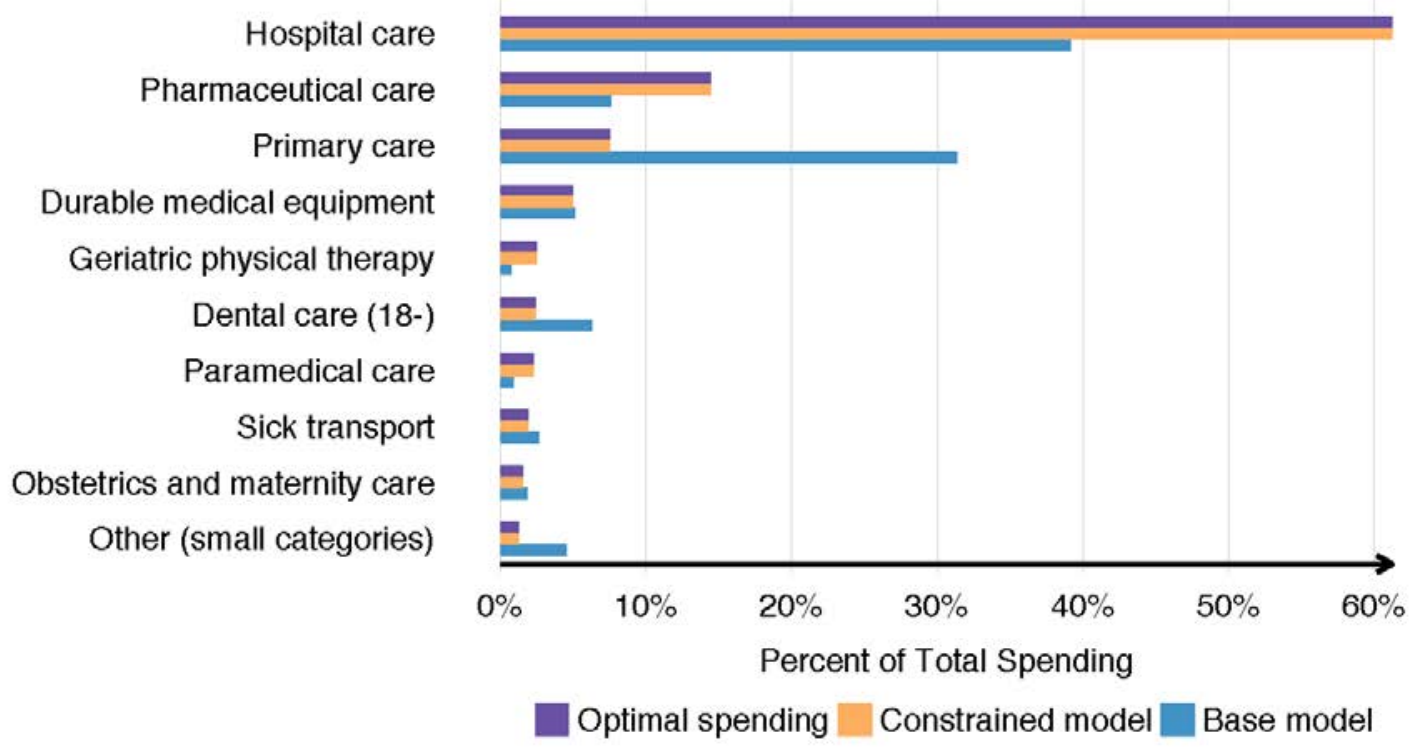

the fact that an individual's use of primary care does not predict unprofitability as strongly as their use of hospital care hospital care (as shown in Figure 3 below). On the other hand, our model implies that the conventional Dutch risk adjustment model pushes plans to allocate "too few" resources to hospital care. 30

Finally, Figure 2 confirms that equilibrium service-level allocations are moved to match the optimal allocations by the constrained risk adjustment model. As expected, the orange and purple bars are equal, indicating that the constrained model completely solves the service-level distortion problem by inducing plans to offer the optimal allocations of spending across services.

\subsection{Incentives for Service-level Distortions: Predictability and Predictiveness}

We now show that the constrained regression method we develop here improves payment system performance not only according to measures of incentives for service-level selection derived from our model but also according to measures of selection incentives developed in the previous literature. Figure 3 shows our measures of predictability (left panel) and predictiveness (right panel) for each of the ten services. As described in Section 4.6.1, predictability is calculated as the correlation between individuals' expected spending on service s and their actual spending on that service. The figure reveals substantial heterogeneity in

\footnotetext{
${ }^{30}$ Despite the fact that the conventional Dutch model leaves plans with incentives to distort service-level spending away from optimal levels, in results not presented here, we find that the Dutch model significantly improves insurer incentives when compared to the case of no risk adjustment. In that extreme case, distortionary insurer incentives are very strong relative to under the conventional Dutch model.
} 
Figure 3: Predictability and Predictiveness
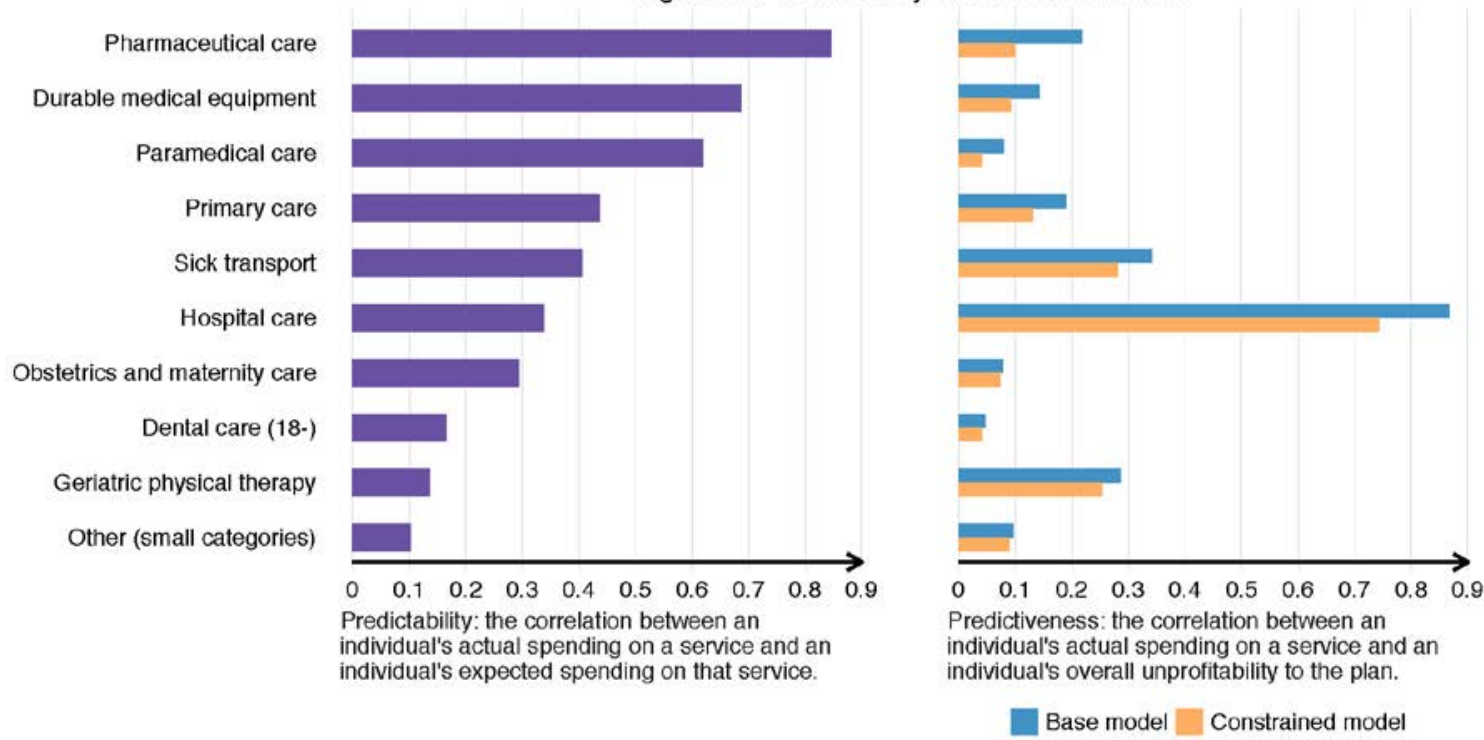

predictability across services with pharmaceutical spending being the most predictable and "other" and geriatric physical therapy spending being the least predictable. Since actual spending (as reflected in $\sigma_{\text {is }}$ ) and expected spending (as reflected in $\widehat{\sigma}_{\text {is }}$ ) are independent of payment weights, the predictability of services is independent of the payment model.

The right panel of Figure 3 shows our predictiveness measure for each of our ten services under two payment models: the conventional Dutch risk adjustment model and the new constrained model. The bars show the correlation between an individual's spending on service s and their overall unprofitability to the plan. Bigger bars signify a higher correlation. Risk adjustment, by transferring funds to more costly enrollees should cause some convergence among these service-specific correlations such that spending on service s has a similar relationship with total profitability as spending on service s'. ${ }^{31}$ It is clear from the figure that the constrained model improves on the conventional Dutch model, driving down the correlation between spending on a service and unprofitability to the plan for all services.

Note that predictiveness only matters for selection incentives if the service is also predictable. Unless a potential enrollee anticipates their level of utilization of a given service, her demand for a given insurance contract is unlikely to respond to changes in the level of rationing of that service. In other words, if a service is not predictable, tight or loose rationing of that service should have no effect on enrollment and profitability. This implies that the results in the right and left panels of Figure 3 combine to form the overall

\footnotetext{
${ }^{31}$ A complete convergence will not occur, nor is it desirable, because it is plan incentives that should be consistent
} across services and those incentives depend on both predictability and predictiveness. 
selection incentives faced by insurers, with services that score high on both predictability and predictiveness being the most vulnerable to service-level distortions.

\section{Redefining Efficient Spending for Purposes of Risk Adjustment: An Illustration}

As discussed in Section 4.4, to implement our methods and measures we assume that the patterns of spending observed in the data represent the optimal levels of spending. This assumption, implicit in much of the risk adjustment literature, is problematic for a variety of reasons described above. We now illustrate how this assumption can be (and sometimes is) relaxed, leaving a full treatment of this insight for future work. ${ }^{32}$

In the Netherlands, regulators already effectively partially relax this assumption. Prior to estimating the payment weights for the Dutch risk adjustment model, data for risk adjustment are modified in order to more accurately capture trends in costs. Risk adjustment payment weights in the Netherlands for year $\mathrm{t}$ are estimated prospectively using medical spending from year $\mathrm{t}-3$ as the dependent variable. Anticipated changes in spending levels between year t-3 and year t (e.g. due to changes in demography), are taken into account by a linear correction of the original service-level spending from $\mathrm{t}-3$. This linear correction may vary across services at the discretion of the analyst. In addition, the data are corrected for changes in the benefit package between year $\mathrm{t}-3$ and year $\mathrm{t}$, which could mean, for instance, that if a certain drug was introduced in year $\mathrm{t}-1$, spending on that drug is added to the risk adjustment data. These modifications are an example of regulators re-defining first-best optimal spending, $\mathrm{x}_{\mathrm{is}}^{*}$, to account for differences between observed spending patterns and the spending patterns regulators believe to be optimal.

In addition to altering the data because of changes in the benefit package or in anticipation of exogenous trends in service use and cost, the data might also be modified prior to estimation to improve the performance of the health care system. Suppose that for reasons unrelated to adverse selection the regulator believes that overall levels of primary care are inefficiently low relative to overall levels of hospital care. ${ }^{33} \mathrm{In}$ this setting, the regulator would want to move money from the overall hospital care allocation to the overall primary care allocation, allowing the individual-specific allocation rules to determine how this shift in funds affects each individual. Our insight is that the regulator can encourage this reallocation of funds via the risk

\footnotetext{
${ }^{32}$ In addition to the discussion here about ways to make ad hoc adjustments to the data, there is an alternative way to modify this assumption. In this paper, we follow the previous literature by assuming observed spending is optimal and using a model to derive equilibrium spending. Alternatively, it may be possible (and perhaps more reasonable) to assume that observed spending is equilibrium spending and use a model to derive optimal spending. Exploring this possibility is beyond the scope of this paper but may represent a promising area for future research.

${ }^{33}$ For example, primary care may be underprovided if health insurance contracts tend to be short-term and consumers switch contracts often.
} 


\section{Figure 4: Differences in Payments for Enrollees with Selected "Healthy" and "Sick" Indicators with and without Changing the Data}

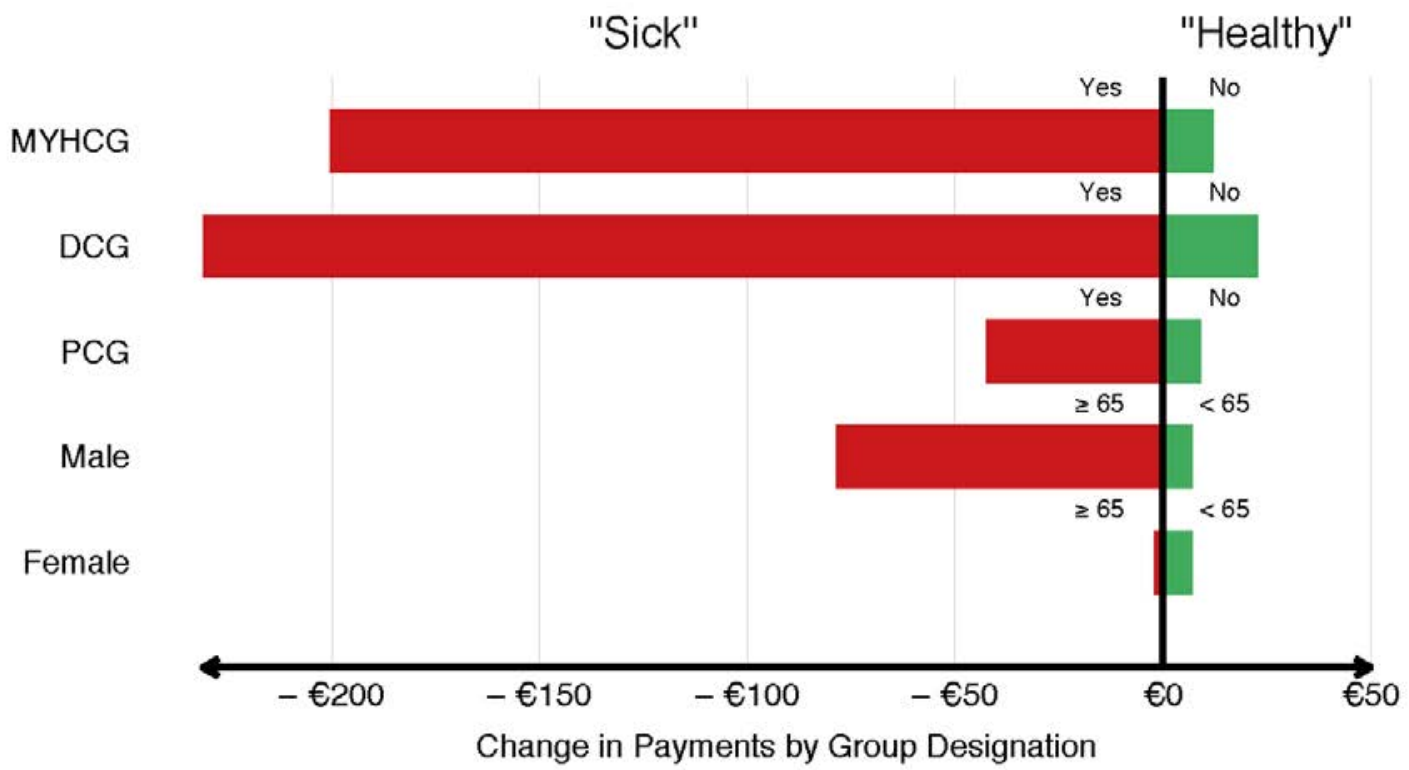

Notes: MYHCG: multiple-year high cost group; DCG: any DCG; PCG: any PCG. For each mutually exclusive partitioning of the population the payment changes weighted by group size sum to zero. Change in payments for the four groups, male $<65$, male $\geq$, female $<65$, and female $z$, must sum to zero.

adjustment model when using the constrained regression model. Instead of estimating the risk adjustment payment weights using observed spending levels as the outcome variable, the regulator can alter the overall levels of spending for each service, use the allocation rules (the sigma's) to map from the overall service-level allocations to individual spending, and then use the modified individual spending variable in a constrained regression to estimate the payment weights. Such an adjustment would result in higher payments for groups of individuals more likely to use primary care at the cost of payments for groups more likely to use hospital care.

As a demonstration we implement this method by shifting 900 million Euros (3\% of total spending) from hospital care to primary care and then re-estimating the constrained regression model. Figure 4 shows how this affects payments for various groups of individuals. The figure presents the same five stratifications of the population from Figure 1. The bars represent the change in payments for each group with the red bars showing changes in payments for the sicker group and the green bars showing changes in payments for the healthier group for each stratification. Note that in all cases, when the data are adjusted to shift resources from hospital care to primary care, payments for the sick go down while payments for the healthy go up. This type of shift in payments implies a shift in incentives, where plans will provide more primary care and less hospital care in order to attract more of the healthy groups who are now more profitable than before. 
Under estimation methods that take into account health plans' decisions on health care spending, transforming the data prior to deriving risk adjustment payment weights would likely improve incentives for resource allocation. When paired with a constrained regression, transformation of data can ensure that the payment model provides incentives to supply exactly the desired pattern of care in equilibrium.

\section{Discussion}

In this paper, we have developed new estimation methods and performance measures for risk adjustment models that generate optimal payment weights according to an explicit economic model of insurer behavior and social welfare as alternatives to the conventional estimation methods and measures that generate payments based on statistical criteria. We assumed the objective is efficiency of resource allocation across medical services. We showed that in this context the only case in which the R-squared is the "right" welfare measure is when 1) health care is regarded as one homogeneous service and 2) health plans can discriminate at the individual level. Since these assumptions are unrealistic, we have proposed a more general welfare measure and alternative estimation methods. Specifically, we have proposed to replace the two-step "estimate-then-evaluate" approach in risk adjustment for health plan payment with a one-step "estimate-tomaximize-the-objective" approach. Since this one-step approach forces regulators to make their objective regarding health plan payment explicit, we believe it is less vulnerable to subjective judgments about the "performance" of a risk adjustment model than the conventional two-step approach.

Our methodology is an application of the principal-agent or mechanism design approach using concepts of economic equilibrium and efficiency. In order to evaluate the performance of a policy tool like health plan payment, it is necessary to anticipate how it will affect market behavior. This calls for a model relating the risk adjusted payments to economic equilibrium. We have adapted approaches from the literature on health plan and consumer behavior to construct a workable model relating the payment weights to equilibrium service allocations decided by plans. Our paper proposes what we argue is a plausible and practical metric for welfare loss. Our methods for deriving payment weights minimize welfare loss subject to equilibrium behavior by plans in an empirically operational fashion. In each of the two major cases, when the number of available risk adjustors exceed or fall short of the number of potential plan actions, we show that the solution to this problem can be found using relatively straightforward variants on the conventional leastsquares regression: the addition of constraints to the regression model in the case of few plan actions and a straightforward transformation of the data in the case of many plan actions.

We have empirically illustrated the case where the number of adjustors exceeds the number of plan actions (few plan actions), using data from the Netherlands. Our empirical results are consistent with earlier 
papers, indicating that under our economic model the Dutch risk adjustment model (of 2015) and its corresponding weights leave substantial incentives for service-level distortion. For example, our predictability and predictiveness measures indicate that by spending an extra euro on pharmaceutical care health plans will attract enrollees who are much less profitable than those who will be attracted by spending an extra euro on primary care. This provides competing health plans with incentives to allocate more money to primary care and less to pharmaceutical care. We show that by adding a set of linear constraints when estimating the payment weights of the Dutch risk adjustment model, incentives for service-level distortion can be eliminated so that the risk adjustment payments push plans toward first-best service allocations.

The solution illustrated in our empirical illustration applies to any setting where the number of adjustors exceeds the number of plan actions. This may be the case for the Dutch risk adjustment model, the German risk adjustment model and the U.S. federal risk adjustment models used in Medicare Advantage and the Marketplaces, which all include over 100 risk adjustor variables. When the number of relevant services exceeds the number of risk adjustor variables this first-best allocation cannot be achieved. In that case the risk adjustment payment weights that minimize, but do not necessarily eliminate, the welfare loss can be found by a linear regression of first-best allocations, $\mathrm{x}_{\mathrm{is}}^{*}$, on the K-by-S transformed $\mathrm{z}$ variables (risk adjustors), $\sum_{\mathrm{s}} \sigma_{\mathrm{is}} \hat{\mathrm{z}}_{\text {gsk }}$, derived in our analytical framework. Switzerland, with its simple risk adjustment model is a potential candidate for implementing this method empirically.

In a setting where regulators are concerned with service-level distortions the concepts of "equilibrium" and "efficiency" applied in this paper are powerful tools not only for estimating risk adjustment payment weights, but also for guiding the choice of risk-adjustor variables to include in the payment model. Presently, risk adjustor variables are included or excluded based on considerations of clinical meaningfulness, game-ability and contribution to fit (Kautter et al., 2014). There are several reasons to reconsider the specification of a risk-adjustment model. Recent research and policy experience implies that, in the US at least, "upcoding" clinically related variables is a serious and costly issue (Geruso and Layton, 2015). Furthermore, application of alternative estimation techniques based on machine learning indicates that statistical fit as measured by R-squared may be achieved with many fewer variables than presently in use (Rose, 2016). Our analyses add an additional reason to reconsider the specification. With a measure of efficiency in hand, the contribution of an additional set of risk adjustors can be evaluated in relation to its ability to improve economic efficiency. A simple and direct way to do this would be to supplement the Rsquared fit criteria with the welfare loss criteria in evaluating the contribution of a set of variables. The contribution of a new set of variables will depend on the present set of adjustors and how well they do in directing incentives for each of the services plans can discriminate on. Our framework implies that - in the case of service-level distortion - risk adjustors should not be evaluated only by the extent to which they reduce "under/overcompensations", but also by their potential to reduce variation in predictability and 
predictiveness across services. The stronger a risk adjustor variable correlates with spending on a particular service, the larger will be its potential to mitigate the welfare loss from allocative inefficiency.

When it comes to a practical implementation of our approach it will be important for regulators to carefully reconsider the assumptions made in this paper. More specifically, the beliefs on how health plans and consumers act in a particular setting may differ from those adopted here. For example, this paper assumes plans set service spending in response to incentives, whereas there might be other limits on servicelevel spending, such as when regulators require a minimum level of access to health care. Additionally, our economic model is based on assumptions of perfect competition, profit-maximization, a fixed premium and symmetric equilibrium. For several reasons these assumptions may deviate from how the market operates in a particular setting. Furthermore, the regulator's objective may differ from the one adopted here. In the Netherlands, for instance, the regulator is not only concerned with service-level distortions but also with other types of selection actions such as specific marketing strategies of health plans. Finally, regulators are concerned with objectives other than economic efficiency, including "fairness" (i.e. premium differences between plans should not reflect differences in health risk), and "quality of care" (e.g. the risk adjustment payments should encourage plans to invest in the quality of care for particular treatments), among others. A formal incorporation of these objectives within a single social welfare function is probably unrealistic. Despite all of the additional objectives, however, regulators still use the R-squared as the primary metric for payment model performance, a measure which also ignores these other objectives and, as we've shown here, has the additional disadvantage that it does not accurately assess the objective it is intended to capture: incentives for service-level selection. Thus, a metric for economic efficiency with respect to service-level allocations of health care spending, such as one constructed here, can still be useful as a way to help policymakers assess the performance of different payment models. 


\section{References}

Bundorf, M. K, J. D. Levin and N. Mahoney. (2012) "Pricing and Welfare in Health Plan Choice," American Economic Review 102(7): 3214-3248.

Carey, C. (2015) “Government Payments and Insurer Benefit Design In Medicare Part D," Working Paper.

Cutler D.M. and Reber S.J. (1998) "Paying for Health Insurance: The Tradeoff between Competition and Adverse Selection," The Quarterly Journal of Economics 113(2): 433-466.

Eijkenaar F, Van Kleef RC, Van Veen SHCM, Van Vliet RCJA. Research for the Dutch risk equalization model of 2015: Estimation of risk equalization weights. Research report (in Dutch), Erasmus University Rotterdam; 2014.

Einav L. and Finkelstein A. (2011) "Selection in Insurance Markets: Theory and Empirics in Pictures," Journal of Economic Perspectives 25(1): 115-138.

Einav L., Finkelstein A. and Cullen M.R. (2010) "Estimating Welfare in Insurance Markets Using Variation in Prices," The Quarterly Journal of Economics 125(3): 877-921.

Einav, L., Finkelstein A. and Levin, J. (2010) "Beyond Testing: Empirical Models of Insurance Markets," Annual Review of Economics 2:311-36.

Ellis R.P. and McGuire, T.G. (2007) "Predictability and Predictiveness in Health Care Spending," Journal of Health Economics 26(1): 25-48.

Ettner, S., Frank, R., McGuire, T. and Hermann, R. (2001), "Risk Adjustment Alternatives in Paying for Behavioral Health Care Under Medicaid," Health Services Research 36(4): 793-811.

Frank R.G., Glazer J. and McGuire T.G. (2000) "Measuring Adverse Selection in Managed Health Care," Journal of Health Economics 19(6): 829-854.

Geruso M. (2016) "Demand Heterogeneity in Insurance Markets: Implications for Equity and Efficiency," Working paper.

Geruso M. and Layton, T. (2015) “Upcoding: Evidence from Medicare on Squishy Risk Adjustment,” NBER Working Paper 21222.

Glazer J. and McGuire T.G. (2000), “Optimal Risk Adjustment of Health Insurance Premiums: an Application to Managed Care,” The American Economic Review 90(4): 1055-1071.

Glazer J. and McGuire T.G. (2002) "Setting Health Plan Premiums to Ensure Efficient Quality in Health Care: Minimum Variance Optimal Risk Adjustment," Journal of Public Economics 84(2): 153-173.

Handel B., Hendel, I, and Whinston M. 2015. "Equilibria in Health Insurance Exchanges: Adverse Selection vs. Reclassification Risk.” Econometrica, vol. 83(4): 1261-1313.

Kautter, J., Pope, G.C., Ingber, M., Freeman, S., Patterson, L., Cohen, M. and Keenan, P. (2014), “The HHSHCC Risk Adjustment Model for Individual and Small Group Markets under the Affordable Care Act," Medicare \& Medicaid Research Review 4(3): E1-E11. 
Kronick, R. and Welch, P.W. (2014), "Measuring Coding Intensity in the Medicare Advantage Program," Medicare \& Medicaid Research Review 4(2): E1-E19.

Layton, T., Ellis, R.P., and McGuire, T.G., (2015) “Assessing Incentives for Adverse Selection in Health Plan Payment Systems,” National Bureau of Economic Research Working Paper 21531, September, 2015.

Lorenz, N. (2015) "Using Quantile and Asymmetirc Least Squares Regression for Optimal Risk Adjustment." Universitat Trier Research Papers in Economics, September 30, 2015

McGuire, T.G., Newhouse, J.P., Normand, S-L., Shi, J. and Zuvekas, S. (2014) "Assessing Incentives for Service-Level Selection in Private Health Insurance Exchanges," Journal of Health Economics 35: 47-63.

Rothschild M and Stiglitz J. 1976. "Equilibrium in Competitive Insurance Markets: An Essay on the Economics of Imperfect Information.” The Quarterly Journal of Economics 90(4): 629-649.

Rose, S. (2016), “A Machine Learning Framework for Plan Payment Risk Adjustment," Health Services Research, DOI: $10.1111 / 1475-6773.12464 .$.

van Barneveld, E., L. Lamers, R. van Vliet and W. van de Ven (2001), "Risk Sharing as a Supplement to Imperfect Capitation: A Tradeoff Between Selection and Efficiency," Journal of Health Economics 20(2): 147-168.

van Veen, S.H.C.M., van Kleef, R.C., van de Ven, W.P.M.M. and van Vliet, R.C.J.A. (2015) "Is There One Measure of Fit that Fits All? A Taxonomy and Review of Measures of Fit for Risk Equalization Models," Medical Care Research and Review, pp 1-24.

van Kleef, R.C., R.C.J.A. van Vliet and W.P.M.M. van de Ven. (2015a) "Overpaying morbidity adjusters in risk equalization models," The European Journal of Health Economics,

DOI 10.1007/s10198-015-0729-2.

van Kleef, R.C., McGuire, TG., van Vliet, R.C.J.A. and van de Ven, W.P.M.M. (2015b) "Improving Risk Equalization with Constrained Regression," National Bureau of Economic Research, Working Paper, 21570, September, 2015. 


\section{Appendix: Estimated Coefficients for Two Models}

\begin{tabular}{|c|c|c|c|}
\hline Risk adjustor variables & $\begin{array}{c}\text { Population } \\
\text { frequency }\end{array}$ & $\begin{array}{c}\text { Base } \\
\text { model }\end{array}$ & \begin{tabular}{|c|c|}
$\begin{array}{c}\text { Constrained } \\
\text { model }\end{array}$ \\
\end{tabular} \\
\hline Intercept & $100.00 \%$ & 203 & -790 \\
\hline Male. 0 & $0.55 \%$ & 3716 & 5898 \\
\hline Male. 1-4 & $2.27 \%$ & 425 & -85 \\
\hline Male. 5-9 & $2.96 \%$ & 289 & -72 \\
\hline Male. 10-14 & $3.11 \%$ & 172 & 410 \\
\hline Male. $15-17$ & $1.81 \%$ & 192 & 629 \\
\hline Male. $18-24$ & $4.29 \%$ & -15 & -38 \\
\hline Male. $25-29$ & $2.94 \%$ & -42 & -58 \\
\hline Male. 30-34 & $2.95 \%$ & -39 & -34 \\
\hline Male. 35-39 & $3.08 \%$ & 0 & 0 \\
\hline Male. $40-44$ & $3.83 \%$ & 75 & 114 \\
\hline Male. $45-49$ & $3.89 \%$ & 187 & 263 \\
\hline Male. 50-54 & $3.67 \%$ & 333 & 499 \\
\hline Male. 55-59 & $3.33 \%$ & 584 & 936 \\
\hline Male. 60-64 & $3.19 \%$ & 813 & 1364 \\
\hline Male. 65-69 & $2.73 \%$ & 1278 & 1643 \\
\hline Male. $70-74$ & $1.90 \%$ & 1661 & 2041 \\
\hline Male. 75-79 & $1.37 \%$ & 2104 & 2401 \\
\hline Male. $80-84$ & $0.89 \%$ & 2248 & 2351 \\
\hline Male. $85-89$ & $0.43 \%$ & 2364 & 2105 \\
\hline Male. $90+$ & $0.15 \%$ & 2542 & 1433 \\
\hline Female. 0 & $0.52 \%$ & 3069 & 5207 \\
\hline Female. 1-4 & $2.17 \%$ & 199 & -154 \\
\hline Female. 5-9 & $2.82 \%$ & 153 & 158 \\
\hline Female. 10-14 & $2.97 \%$ & 142 & 514 \\
\hline Female. 15-17 & $1.72 \%$ & 324 & 416 \\
\hline Female. 18-24 & $4.18 \%$ & 305 & 145 \\
\hline Female. 25-29 & $2.96 \%$ & 774 & 985 \\
\hline Female. 30-34 & $2.99 \%$ & 935 & 1549 \\
\hline Female. 35-39 & $3.14 \%$ & 546 & 977 \\
\hline Female. 40-44 & $3.83 \%$ & 309 & 439 \\
\hline Female. 45-49 & $3.86 \%$ & 352 & 387 \\
\hline Female. 50-54 & $3.68 \%$ & 463 & 578 \\
\hline Female. 55-59 & $3.34 \%$ & 573 & 773 \\
\hline Female. 60-64 & $3.18 \%$ & 733 & 1110 \\
\hline Female. 65-69 & $2.78 \%$ & 1043 & 1162 \\
\hline Female. 70-74 & $2.07 \%$ & 1362 & 1534 \\
\hline Female. 75-79 & $1.71 \%$ & 1703 & 2019 \\
\hline
\end{tabular}




\begin{tabular}{|c|c|c|c|}
\hline Risk adjustor variables & $\begin{array}{l}\text { Population } \\
\text { frequency }\end{array}$ & $\begin{array}{c}\text { Base } \\
\text { model }\end{array}$ & $\begin{array}{c}\text { Constrained } \\
\text { model }\end{array}$ \\
\hline Female. 80-84 & $1.37 \%$ & 1955 & 2296 \\
\hline Female. 85-89 & $0.89 \%$ & 2165 & 2341 \\
\hline Female. $90+$ & $0.48 \%$ & 2125 & 1181 \\
\hline No PCG a & $82.03 \%$ & 201 & 637 \\
\hline Glaucoma & $0.85 \%$ & 279 & 346 \\
\hline Thyroid disorders & $1.64 \%$ & 83 & -181 \\
\hline Mental disorders & $0.53 \%$ & 95 & 1243 \\
\hline Depressive disorder & $2.67 \%$ & 184 & -636 \\
\hline Peripheral neuropathy & $0.38 \%$ & 1159 & 157 \\
\hline Hypercholesterolemia & $5.30 \%$ & 178 & -620 \\
\hline Diabetes II without hypertension & $0.63 \%$ & 531 & -1868 \\
\hline COPD / severe asthma & $1.16 \%$ & 1565 & 1165 \\
\hline Asthma & $2.16 \%$ & 573 & 643 \\
\hline Diabetes II with hypertension & $1.40 \%$ & 845 & -1511 \\
\hline Epilepsy & $0.48 \%$ & 834 & -245 \\
\hline Crohn's disease / Colitis ulcerosa & $0.20 \%$ & 818 & 2881 \\
\hline Heart diseases & $2.21 \%$ & 1500 & 1242 \\
\hline Rheumatoid arthritis (TNF- $\alpha$ ) & $0.19 \%$ & 14164 & 14623 \\
\hline Rheumatoid arthritis (other) & $0.32 \%$ & 1478 & 2813 \\
\hline Parkinson's disease & $0.14 \%$ & 2176 & 3527 \\
\hline Diabetes type I & $1.29 \%$ & 1361 & 649 \\
\hline Transplantations & $0.15 \%$ & 89 & 6361 \\
\hline Cystic fibrosis / Pancreatic disease & $0.04 \%$ & 3021 & 15999 \\
\hline Disorders of brain/ spinal cord & $0.07 \%$ & 1511 & 4128 \\
\hline Cancer & $0.09 \%$ & 3697 & 9279 \\
\hline Hormone-sensitive tumors & $0.35 \%$ & -712 & -2226 \\
\hline HIV/AIDS & $0.08 \%$ & 2826 & 29936 \\
\hline Kidney disorders & $0.07 \%$ & 7201 & 15969 \\
\hline No DCG b & $91.00 \%$ & 0 & 0 \\
\hline DCG1 & $0.67 \%$ & 391 & 400 \\
\hline DCG2 & $1.49 \%$ & 560 & 750 \\
\hline DCG3 & $1.11 \%$ & 635 & 659 \\
\hline DCG4 & $1.80 \%$ & 1011 & 3436 \\
\hline DCG5 & $1.16 \%$ & 1618 & 2657 \\
\hline DCG6 & $1.26 \%$ & 2002 & 3813 \\
\hline DCG7 & $0.55 \%$ & 3225 & 9061 \\
\hline DCG8 & $0.12 \%$ & 3989 & 9721 \\
\hline DCG9 & $0.30 \%$ & 3847 & 6950 \\
\hline DCG10 & $0.33 \%$ & 7307 & 14332 \\
\hline DCG11 & $0.04 \%$ & 8722 & 14286 \\
\hline
\end{tabular}




\begin{tabular}{|c|c|c|c|}
\hline Risk adjustor variables & $\begin{array}{l}\text { Population } \\
\text { frequency }\end{array}$ & $\begin{array}{c}\text { Base } \\
\text { model }\end{array}$ & $\begin{array}{c}\text { Constrained } \\
\text { model }\end{array}$ \\
\hline DCG12 & $0.07 \%$ & 8608 & 20788 \\
\hline DCG13 & $0.04 \%$ & 15876 & 32097 \\
\hline DCG14 & $0.04 \%$ & 65152 & 63374 \\
\hline DCG15 & $0.01 \%$ & 51005 & 140811 \\
\hline ZIP-code cluster 1 & $9.91 \%$ & 169 & 479 \\
\hline ZIP-code cluster 2 & $9.88 \%$ & 124 & 351 \\
\hline ZIP-code cluster 3 & $9.97 \%$ & 101 & 254 \\
\hline ZIP-code cluster 4 & $9.86 \%$ & 84 & 215 \\
\hline ZIP-code cluster 5 & $10.01 \%$ & 68 & 203 \\
\hline ZIP-code cluster 6 & $9.91 \%$ & 64 & 171 \\
\hline ZIP-code cluster 7 & $9.98 \%$ & 50 & 129 \\
\hline ZIP-code cluster 8 & $9.98 \%$ & 38 & 78 \\
\hline ZIP-code cluster 9 & $10.17 \%$ & 24 & 44 \\
\hline ZIP-code cluster 10 & $10.32 \%$ & 0 & 0 \\
\hline Age $=0-17$ or $65+$ & $37.67 \%$ & 0 & 0 \\
\hline Disability beneficiaries. $15-34$ & $0.91 \%$ & 647 & -969 \\
\hline Disability beneficiaries. 34-44 & $0.77 \%$ & 803 & -50 \\
\hline Disability beneficiaries. $45-54$ & $1.30 \%$ & 720 & 88 \\
\hline Disability beneficiaries. 55-64 & $2.02 \%$ & 596 & 362 \\
\hline General beneficiaries. 15-34 & $0.57 \%$ & 267 & -260 \\
\hline General beneficiaries. $34-44$ & $0.55 \%$ & 353 & -214 \\
\hline General beneficiaries. 45-54 & $0.60 \%$ & 412 & 43 \\
\hline General beneficiaries. 55-64 & $0.48 \%$ & 368 & 327 \\
\hline Students. $18-34$ & $3.20 \%$ & -238 & -233 \\
\hline Self-employed. 15-34 & $0.78 \%$ & -116 & -155 \\
\hline Self-employed. 34-44 & $1.27 \%$ & -111 & -112 \\
\hline Self-employed. 45-54 & $1.32 \%$ & -146 & -156 \\
\hline Self-employed. 55-64 & $0.79 \%$ & -152 & -148 \\
\hline Other. 15-34 & $14.84 \%$ & 0 & 0 \\
\hline Other. 34-44 & $11.29 \%$ & 0 & 0 \\
\hline Other. 45-54 & $11.88 \%$ & 0 & 0 \\
\hline Other. 55-64 & $9.75 \%$ & 0 & 0 \\
\hline No MYHCG $^{c}$ & $94.24 \%$ & 0 & 0 \\
\hline $2 \mathrm{x}$ costs in top- $10 \%$ & $1.01 \%$ & 2661 & 6082 \\
\hline $3 \mathrm{x}$ costs in top- $15 \%$ & $2.30 \%$ & 2318 & 3155 \\
\hline $3 \mathrm{x}$ costs in top- $10 \%$ & $1.05 \%$ & 3680 & 4370 \\
\hline $3 \mathrm{x}$ costs in top- $7 \%$ & $0.78 \%$ & 5692 & 6085 \\
\hline $3 x$ costs in top- $4 \%$ & $0.46 \%$ & 9661 & 9066 \\
\hline $3 \mathrm{x}$ costs in top- $1.5 \%$ & $0.15 \%$ & 25836 & 37142 \\
\hline No DMECG ${ }^{\mathrm{d}}$ & $99.17 \%$ & 0 & 0 \\
\hline
\end{tabular}




\begin{tabular}{|l|c|c|c|}
\hline Risk adjustor variables & $\begin{array}{c}\text { Population } \\
\text { frequency }\end{array}$ & $\begin{array}{c}\text { Base } \\
\text { model }\end{array}$ & $\begin{array}{c}\text { Constrained } \\
\text { model }\end{array}$ \\
\hline Insulin pumps & $0.12 \%$ & 422 & -3319 \\
\hline Catheters & $0.39 \%$ & 1308 & -1212 \\
\hline Stoma & $0.31 \%$ & 1801 & -929 \\
\hline Trachea-stoma & $0.02 \%$ & 6546 & 2464 \\
\hline Address >15 residents. 0-17 & $0.06 \%$ & 244 & -1059 \\
\hline Address >15 residents. 18-64 & $0.38 \%$ & 169 & 480 \\
\hline Address >15 residents. 65+ & $0.72 \%$ & 321 & 5820 \\
\hline Income deciles 1-3.0-17 & $6.25 \%$ & 27 & -110 \\
\hline Income deciles 1-3.18-64 & $18.57 \%$ & 53 & 12 \\
\hline Income deciles 1-3.65+ & $4.81 \%$ & 200 & -269 \\
\hline Income deciles 4-7. 0-17 & $8.34 \%$ & -5 & -115 \\
\hline Income deciles 4-7.18-64 & $24.79 \%$ & 48 & 23 \\
\hline Income deciles 4-7.65+ & $6.41 \%$ & 44 & -166 \\
\hline Income deciles. 8-10.0-17 & $6.25 \%$ & 0 & 0 \\
\hline Income deciles. 8-10.18-64 & $18.59 \%$ & 0 & 0 \\
\hline Income deciles. 8-10.65+ & $4.81 \%$ & 0 & 0 \\
\hline 65-. no morbidity e & $70.38 \%$ & 0 & 0 \\
\hline 65-. morbidity & $12.86 \%$ & 618 & 1541 \\
65+. no morbidity & $6.89 \%$ & 0 & 0 \\
65+. morbidity & $9.88 \%$ & 642 & 2272 \\
\hline
\end{tabular}

a PCG $=$ Pharmacy-based Cost Group

${ }^{\mathrm{b}}$ DCG $=$ Diagnostic-based Cost Group

c MYHCG $=$ Multiple-Year High Cost Group

d DMECG $=$ Durable Medical Equipment Cost Group

e Morbidity is operationalized as having at least one PCG, DCG, MYHCG or DMECG. 